\title{
Baroclinic Effect on Modeling Deep Flow in Brown Passage, BC, Canada
}

\author{
Yuehua Lin *, David B. Fissel, Todd Mudge and Keath Borg \\ ASL Environmental Sciences Inc., \#1-6703 Rajpur Place, Victoria, BC V8M 1Z5, Canada; \\ dfissel@aslenv.com (D.B.F.); tmudge@aslenv.com (T.M.); kborg@aslenv.com (K.B.) \\ * Correspondence: alin@aslenv.com; Tel.: +1-250-656-0177 (ext. 146)
}

Received: 4 August 2018; Accepted: 8 October 2018; Published: 12 October 2018

\begin{abstract}
Brown Passage is a deep (up to $200 \mathrm{~m}$ ) ocean channel connecting the western offshore waters of Hecate Strait and Dixon Entrance on the Pacific continental shelf with the eastern inland waters of Chatham Sound in Northern British Columbia, Canada. A high-resolution 3D finite difference hydrodynamic model, COastal CIRculation and SEDiment transport Model (COCIRM-SED), was developed in 2010 and 2013 to determine the tidal and wind-driven currents of this area. The barotropic model results for ocean currents were found to be in reasonably good agreement with the historical ocean current observations at near-surface and middle depth available for Brown Passage. Operated from October 2014 to April 2015, the first modern oceanographic measurement program in Brown Passage found surprisingly strong near-bottom currents (the 99th percentile current speed reaches $53 \mathrm{~cm} / \mathrm{s}$ at $196 \mathrm{~m}$ ). As a result, the COCIRM-SED model was modified and rerun, with the most important change incorporating water density/salinity fields as modeled variables. This change led to considerable improvements in the ability of the model to generate episodes of relatively strong currents in the bottom layers. The bottom intensification in ocean currents in Brown Passage is shown to be due to semi-diurnal internal tides, which were not previously included in the barotropic version of the 3D model. This finding for the near-bottom flow from the qualitative modeling study is important for applications of the potential sediment deposition and resuspension studies.
\end{abstract}

Keywords: Brown Passage; Chatham Sound; internal tides; circulation; numerical model; stratification; barotropic; baroclinic

\section{Introduction}

Brown Passage is a deep (up to $200 \mathrm{~m}$ below chart datum, i.e., the reference level for depths used on a nautical chart) ocean channel connecting the western offshore waters of Hecate Strait and Dixon Entrance on the Pacific continental shelf with the eastern inland waters of Chatham Sound in Northern British Columbia, Canada (Figure 1). Where Chatham Sound is a semi-enclosed inland sea spanning a total distance of approximately $70 \mathrm{~km}$ from south to north and has width of $15-25 \mathrm{~km}$ with water depths generally less than $200 \mathrm{~m}$ [1]. On its western side, it is separated from the more exposed open waters of Dixon Entrance and Hecate Strait by several island groups separated by channels or passages. Among them the two largest and deepest passages are the eastward extension of Dixon Entrance to the north of Dundas Island; and Brown Passage in central Chatham Sound, which are the most important channels allowing the exchanges of water and wave energy with the larger water bodies to the west. 


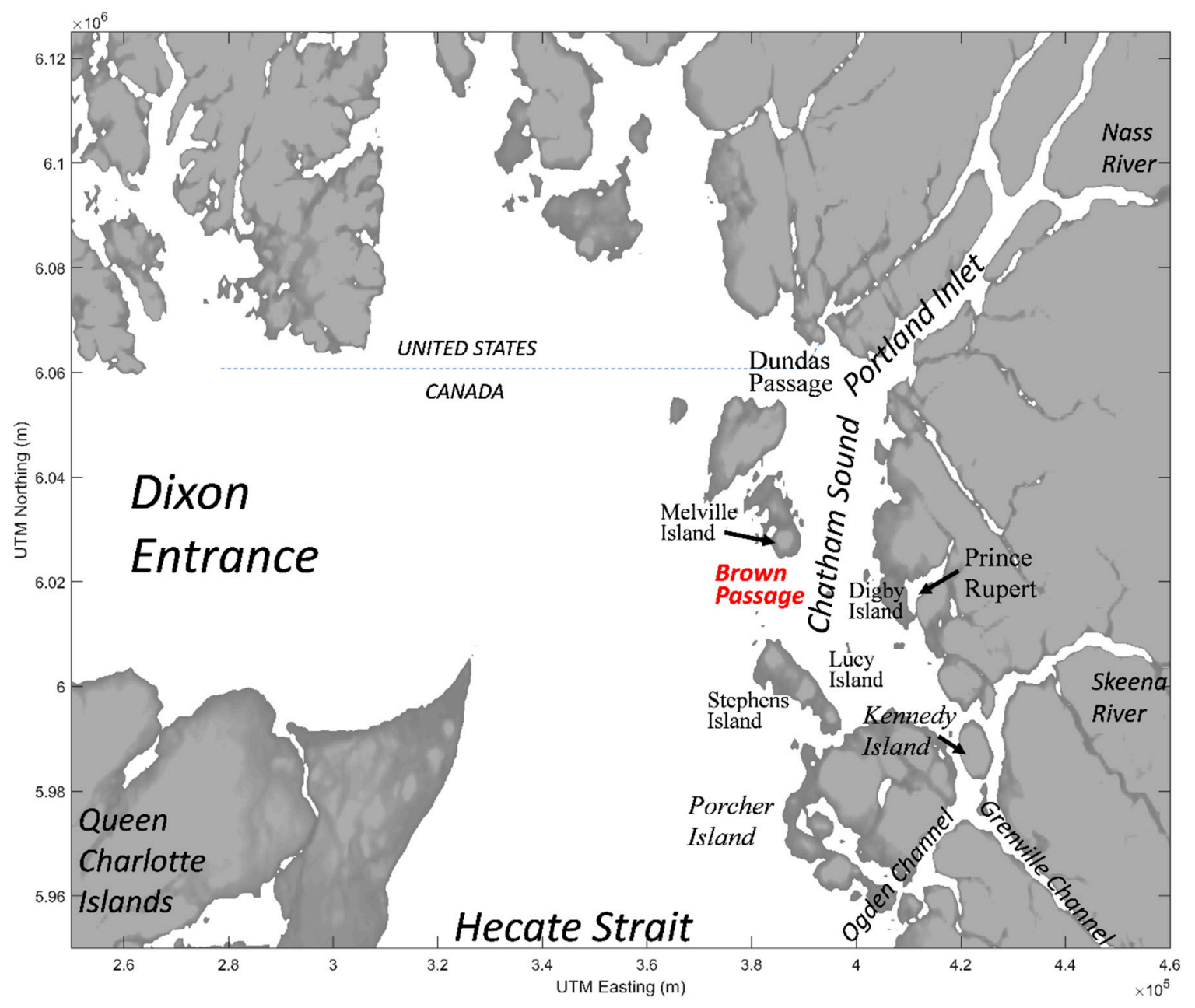

Figure 1. Location of Brown Passage (in red) based on gridded coastline data from gridded bathymetry data (retrieved from the website of the British Oceanographic Data Centre: https:/ /www.gebco.net/ data_and_products/gridded_bathymetry_data/).

The ocean currents in Chatham Sound are highly variable due to a combination of forcing by the large mean tidal range within this area, seasonally strong winds, and large peak freshwater discharges from the Skeena and Nass Rivers. Chatham Sound is characterized by lower salinity ( 20 Practical Salinity Unit (PSU)) near-surface waters on its eastern side, due to the Skeena River inflow to Southern Chatham Sound [1]. More saline waters present on the western side of the Chatham Sound result from the exchange through Brown Passage and other connecting channels with the higher salinity waters of Hecate Strait and Dixon Entrance.

Oceanographic research of this complex oceanic- and river-dominated inland waterway [2] is being driven by industrial activities related to the expansion of the port of Prince Rupert (Figure 1), along with high levels of marine biological productivity and a very active regional fishery in Chatham Sound [3]. Recent research into this oceanic environment is motivated by studies of the possible use of this area for disposal at sea of dredged sediments arising from expansion of marine terminals in and around the Prince Rupert harbor in Chatham Sound [2]. A better understanding of hydrodynamics throughout the whole water column in Brown Passage is required, for the potential short-term sediment transport and long-term resuspension processes with ocean currents.

The spatial extent of the surface expression of the sediment plume from the Skeena River was derived using historical $30 \mathrm{~m}$ resolution LANDSAT imagery (available online from the US Geological Survey). The LANDSAT satellite, LANDSAT-8, which became operational in 2012-2013, has much better radiometric sensitivity $(10 \times$ Landsat 7$)$ which makes it more useful for water applications 
involving subtle signals such as river plumes. One LANDSAT-8 scene, 28 August 2013 (Skeena River discharge of $665 \mathrm{~m}^{3} / \mathrm{s}$ ) was selected and enhanced, as shown in Figure 2 (Figure 5 in [1]). The more sensitive detection of the LANDSAT-8 satellite image scene reveals that the Skeena River plume is detectable along the eastern half of Chatham Sound into the northern half of Chatham Sound. However, commensurate with the relatively low discharges, the Skeena River plume is confined to the estuarine area with a secondary area of enhanced turbidity levels in the area as far northwest as the Digby Island (Figure 1).

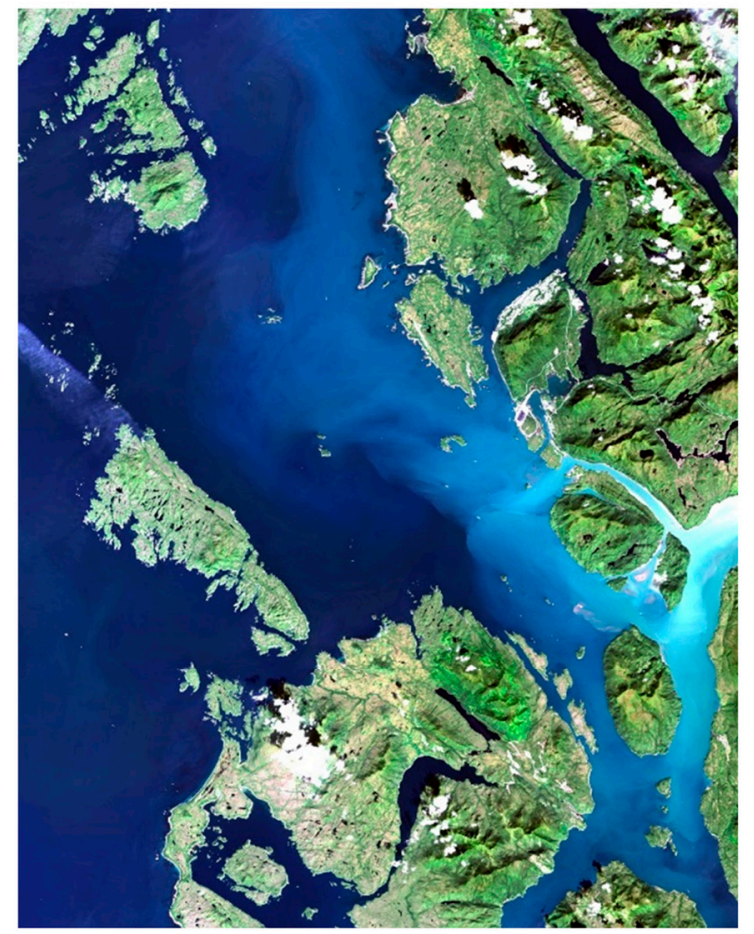

(a)

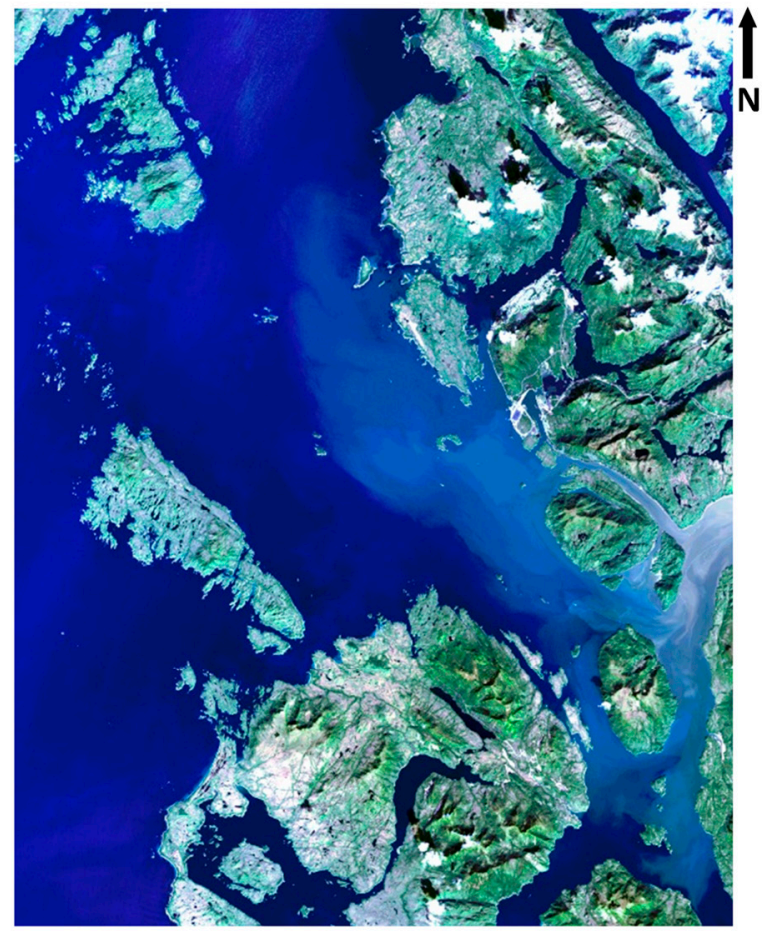

(b)

Figure 2. Enhanced Landsat 8 satellite image for (a) 28 August 2013 (ebb flow, under $665 \mathrm{~m}^{3} / \mathrm{s}$ river discharge from the Skeena River) and (b) 5 April 2015 (flood flow, under $200 \mathrm{~m}^{3} / \mathrm{s}$ river discharge from the Skeena River).

The pathways of freshwater from the Skeena River are highly dependent on the Skeena River discharge values [4]. Under average discharges, about $70 \%$ of the freshwater discharge leaves on the eastern side of central and northern Chatham Sound, where it merges with Nass River freshwater and exits via Dixon Entrance. Only 30\% of the freshwater leaves Chatham Sound through the southern and central passages, with half of this being by the way on the west (e.g., Brown Passage, see Figure 3). During late May and early June peak discharges (freshet) of the Skeena and Nass rivers, the freshwater leaves the Sound via all the passages with the greatest flux through Dundas Passage (Figure 1). Nass River discharge also affects Chatham Sound salinity, but its seasonal variability is very similar to Skeena River discharges, except during the fall season, due to a greater effect from precipitation. During freshet, Nass River water extends as far south as Melville Island (Figure 1). Due to the large mean tidal range of Chatham Sound, the salinity, temperature, and freshwater time series at fixed locations were observed to exhibit variability at tidal periods. During periods of unsteady river discharges, large cells of relatively fresh water are discharged into the Sound from the Skeena River; these are gradually dispersed under the influence of the large tides, winds, and the kinetic and potential energy of the freshwater flows themselves. 


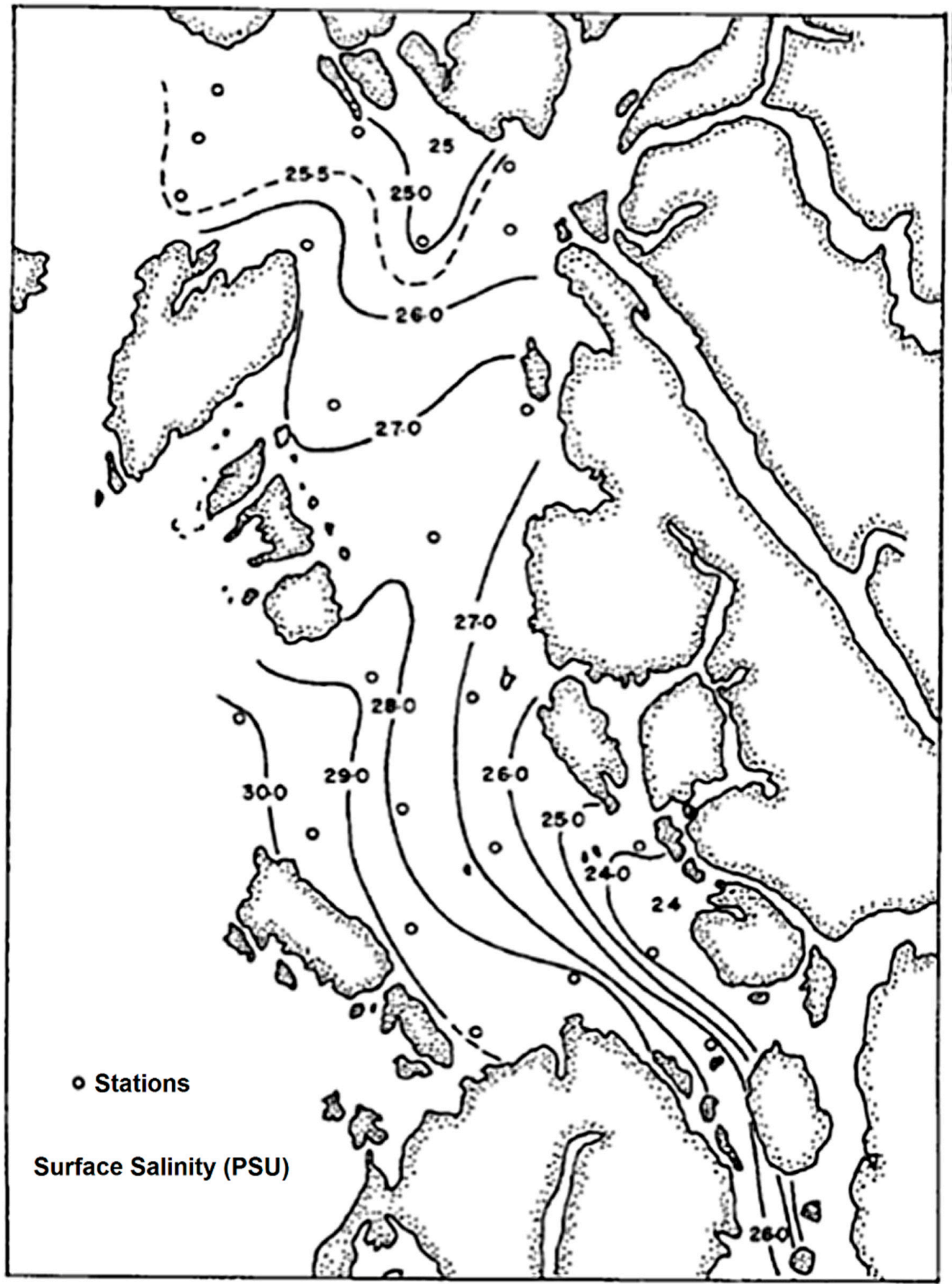

Figure 3. Surface salinity pattern during normal river conditions (under $700-1000 \mathrm{~m}^{3} / \mathrm{s}$ river discharge from the Skeena River), 10-19 August 1948 (Figure 6 in [4]).

Historical conductivity temperature depth (CTD) and bottle data extracted from the Department of Fisheries and Oceans (DFO) database (see http:/ / www.pac.dfo-mpo.gc.ca/science/oceans/datadonnees/index-eng.html) for British Columbia (BC) coastal waters (from 183 sites) were examined for Chatham Sound domain by Lin and Fissel (2018) [1]. Each CTD/bottle site provided a vertical profile of the temperature and salinity. During the freshet season of the Skeena River, i.e., June to August (summer), Southern Chatham Sound features lower salinity (as low as 20 PSU) and a wide temperature 
range from 6 to $15{ }^{\circ} \mathrm{C}$. During non-freshet seasons (winter: December to February, spring: March to May, and fall: September to November), Southern Chatham Sound has lower salinity (25 PSU) at surface, and temperature ranged only from 7 to $8^{\circ} \mathrm{C}$ in winter, 6 to $7^{\circ} \mathrm{C}$ in spring, and 8 to $10^{\circ} \mathrm{C}$ in fall. Surface salinity is lower than in freshet (summer) season. Water is mainly uniform for both temperature and salinity in Western Chatham Sound, except during summer time (it might be affected by limited data availability as well). However, direct observations for ocean currents in Brown Passage are very rare. Ocean current data were collected in fall 1991 at the DFO ocean current mooring site (CP02) located near the regional ocean disposal site (Figure 4).

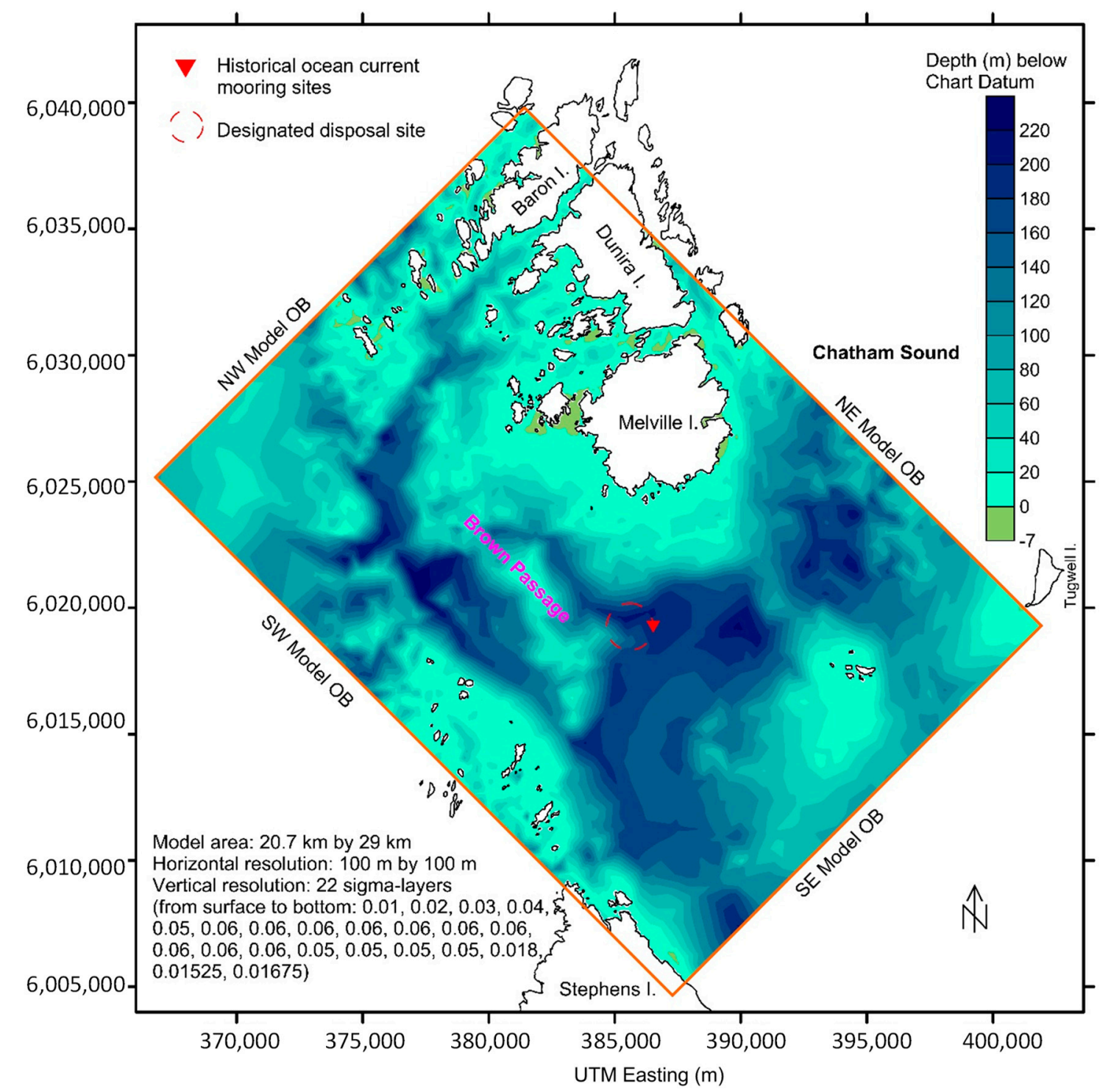

Figure 4. A map of water depths in Brown Passage (meters below chart datum) and the model domain.

The remainder of the paper is arranged as follows. A brief overview of the barotropic modeling is presented in Section 2. The observational data and analysis are presented in Section 3. Section 4 presents the baroclinic modelling and the comparison between model results and observations near the bottom. The final section is a summary and conclusion. 


\section{Previous Modeling Studies}

The circulation of the larger areas of the BC north coast, adjoining Chatham Sound, including Queen Charlotte Sound, Hecate Strait, and Dixon Entrance, has been studied through numerical modeling methods. Hannah et al. (1991) described the wind-driven (no tides), depth-averaged circulation in Queen Charlotte Sound and Hecate Strait [5]. Ballantyne et al. (1996) used a 3D finite element model to compute the buoyancy-driven flows, as well as the barotropic tides of the BC north coast [6]. The tidal currents of the BC north coast have also been modeled by Flather (1987) [7] for the northeast Pacific Ocean; Foreman et al. (1993) [8] for the barotropic tide in the BC north coast; Cummins and Oey (1997) [9] for the barotropic and baroclinic tides of the BC north coast; and Foreman et al. (2000) [10] for assimilating satellite altimeter observations into a barotropic tidal model over the northeast Pacific Ocean. Brown Passage was included in the much larger model BC north coast model domains, but the availability and validity of the model circulation results for Brown Passage were compromised by the poor spatial resolution (e.g., coarser than $1 \mathrm{~km}$ in the horizontal).

A much higher spatial resolution 3D finite difference numerical model, COastal CIRculation and SEDiment transport Model (COCIRM-SED; [11-14]), was developed by Jiang and Fissel in 2012 [2]. This model was applied to determine the tidal and wind-driven currents in Brown Passage and used to simulate the transport and deposition of sediments released from disposal at sea activities. COCIRM-SED is a highly integrated model, consisting of five submodules, including circulation, wave, multisize sediment transport, morphodynamics, and water quality. The model can be operated on either an integrated or an individual module basis.

In the barotropic modeling of Brown Passage [2], the COCIRM-SED model was operated over a numerical model domain for the full area of Brown Passage, with a total area of $20.7 \mathrm{~km}$ by $29 \mathrm{~km}$ (Figure 4). A horizontal grid size resolution of $100 \mathrm{~m}$ by $100 \mathrm{~m}$ was used for the model area. In the vertical, the model used 22 sigma-layers with higher resolutions realized near the surface and bottom. The depths of model layers are computed as (Sigma-layer thickness) $\times($ Total water depth) $=\Delta \sigma H$. The digital bathymetric data set, in the format of Universal Transverse Mercator (UTM) Easting, UTM Northing, and seabed elevation relative to chart datum, was gridded to provide suitable representation of the water depths in the model. The model was forced by tidal height elevations spanning four open boundaries and by surface winds. The four model open boundaries consist of the four adjoining sides of Brown Passage (Figure 4). The forcing at the four open boundaries are limited to tidal elevations and do not include wind forced flows. Tidal elevations at these four open boundaries were derived from 7 major tidal height constituents $(\mathrm{O} 1, \mathrm{P} 1, \mathrm{~K} 1, \mathrm{~N} 2, \mathrm{M} 2, \mathrm{~S} 2, \mathrm{~K} 2)$ using the DFO standard tidal prediction program [15]. The tidal constituents for the reference Qlawdzeet Anchorage, port of Prince Rupert, and Lawyer Islands, were obtained from Canadian Hydrographic Service of DFO (Table 1). Coriolis force was also activated.

Table 1. Tidal constituents at tide gauge stations used for model open boundary conditions.

\begin{tabular}{ccccccc}
\hline Tide Gauge & \multicolumn{2}{c}{$\begin{array}{c}\text { Qlawdzeet Anchorage } \\
\text { (\#9315) }\end{array}$} & \multicolumn{2}{c}{ Prince Rupert (\#9354) } & Lawyer Islands (\#9312) \\
\hline $\begin{array}{c}\text { Tidal } \\
\text { Constituents }\end{array}$ & $\begin{array}{c}\text { Amplitude } \\
(\mathbf{m})\end{array}$ & Phase (deg) & $\begin{array}{c}\text { Amplitude } \\
(\mathbf{m})\end{array}$ & Phase (deg) & $\begin{array}{c}\text { Amplitude } \\
\text { (m) }\end{array}$ & Phase (deg) \\
\hline Z0 & 369.00 & 0.00 & 387.09 & 0.0 & 387.09 & 0.00 \\
O1 & 30.78 & 129.80 & 31.25 & 132.46 & 31.25 & 132.44 \\
P1 & 15.36 & 136.60 & 16.06 & 135.84 & 16.06 & 135.82 \\
K1 & 49.38 & 139.60 & 51.44 & 139.48 & 51.44 & 139.46 \\
N2 & 34.53 & 14.40 & 39.52 & 14.9 & 39.52 & 14.87 \\
M2 & 183.82 & 34.90 & 195.65 & 35.79 & 195.65 & 35.76 \\
S2 & 57.79 & 56.70 & 64.45 & 59.26 & 64.45 & 59.23 \\
K2 & 16.82 & 48.50 & 17.38 & 50.65 & 17.38 & 50.62 \\
\hline
\end{tabular}


This model run involved both tidal forcing at the open boundaries and surface wind forcing using measured hourly winds at the Prince Rupert airport weather station for the same period. As shown in Figure 5a, the dominant wind directions in terms of frequency of occurrence and higher wind speeds are from the south to southeast. Wind forcing is applied as a space-uniform but time-varying value on the model grids.

The model was initially tested with a calibration run. Various physical parameters, mainly bottom drag coefficient and horizontal and vertical eddy diffusivity coefficients, as well as major tidal constituent phases, were repetitively adjusted to achieve optimal agreement with the observations and physically reasonable flow patterns in Brown Passage. The Smagorinsky eddy parameterization [16] was used for horizontal diffusivity with coefficient $C=0.08$. The background vertical diffusion and viscosity were set to $10^{-6} \mathrm{~m}^{2} / \mathrm{s}$ with a MY2.5 (Mellor and Yamada) [17] turbulence closure. The bottom roughness parameter was set to $0.001 \mathrm{~m}$ with a value of 0.015 for the bottom drag coefficient. Readers are referred to Jiang and Fissel (2011) [2] for more details on the model setup and development.

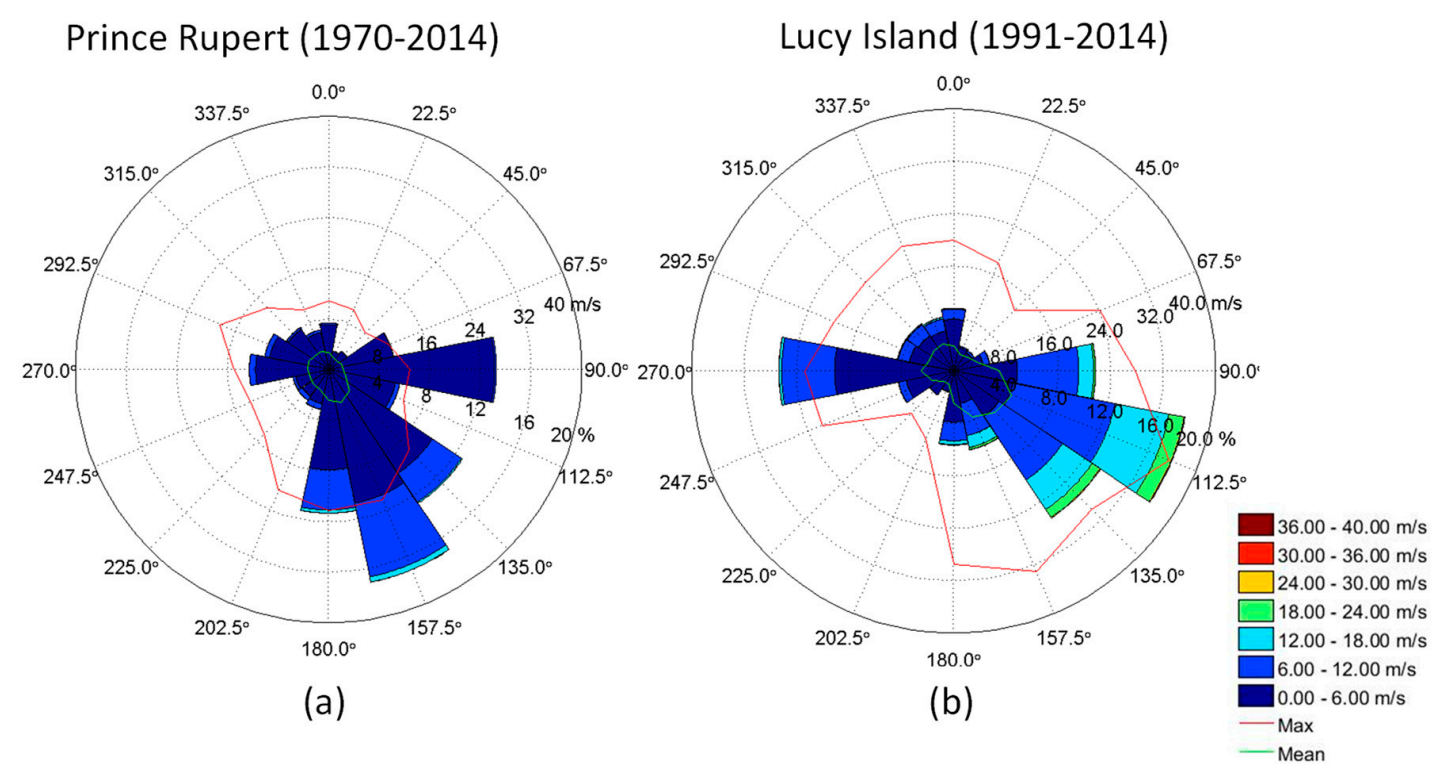

Figure 5. Compass rose plots for wind speed and direction distributions measured at (a) Prince Rupert Airport and (b) Lucy Island (see Figure 1). The wind datasets were obtained from the Meteorological Service of Canada, Environment and Climate Change Canada.

The model was operated for a 17-day-long fall period (5-22 October 1991) and compared with ocean current data at the DFO current meter mooring site located to the southeast of Melville Island (Figure 4). The model results for ocean currents were found to be in reasonably good agreement with the two sets of ocean current observations at $15 \mathrm{~m}$ (Figure 6) and $98 \mathrm{~m}$ (Figure 7), notably, the similarity of the large tidal currents of 6-12 September, and the good agreement in the tidal current directions especially at $15 \mathrm{~m}$ depth of the model results with the data available for Brown Passage [2]. A statistical analysis of the verification model results shows that the correlation coefficients between modeled and measured current speeds and directions are greater than 0.5 near the surface. Relatively weak correlation with a coefficient at about 0.4 occurs for the verification case at $98 \mathrm{~m}$ depth. Readers are referred to Jiang and Fissel (2011) [2] for more details on the model calibration and verification.

Based on the generally favorable model verification results, it was concluded that the circulation module was reasonably well validated and is, thus, suitable for simulating disposal sediment transport and fate in Brown Passage. Based on these results, Brown Passage was thought to be generally well mixed through the middle and lower parts of the water column. 

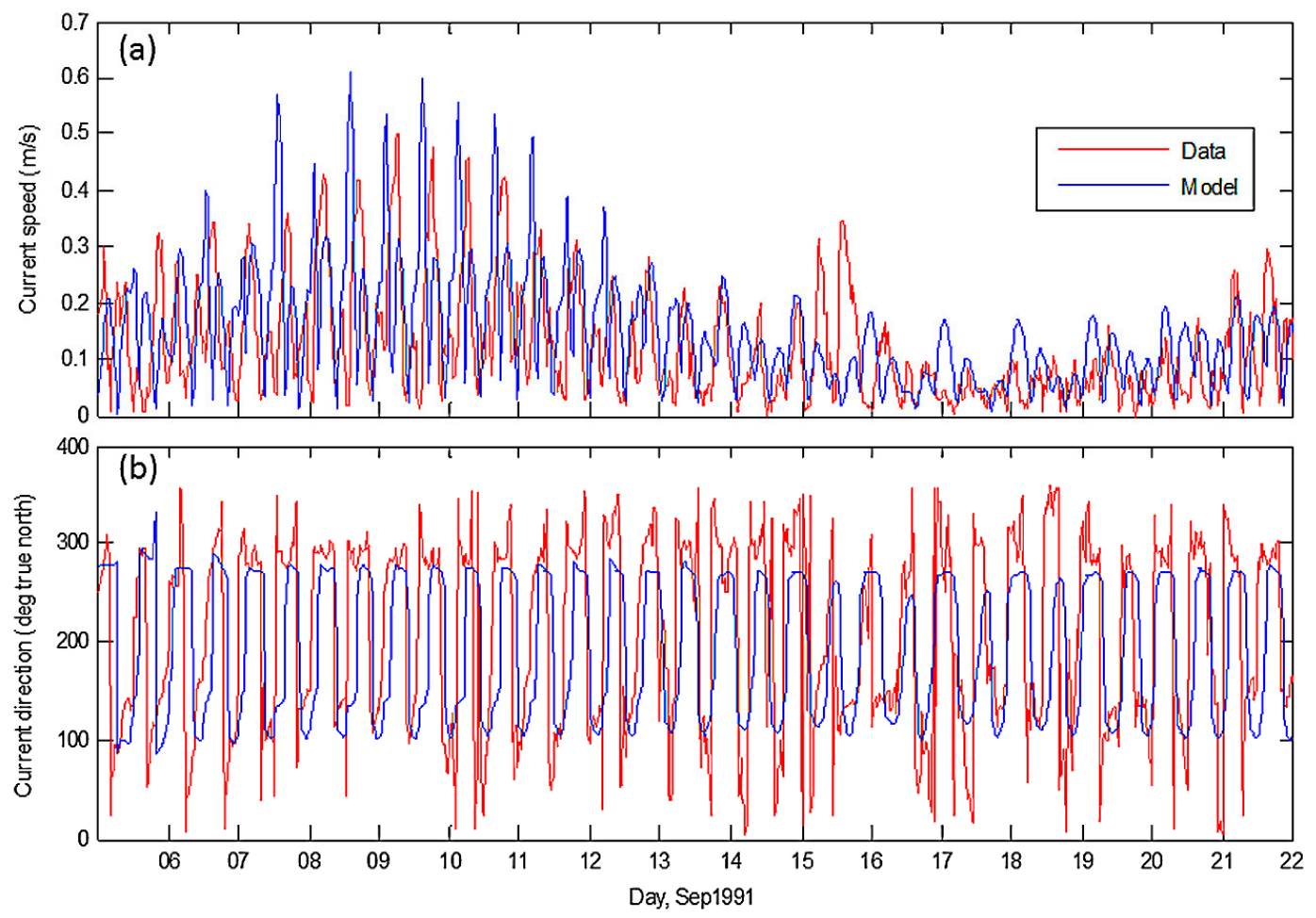

Figure 6. Modeled and measured results of current (a) speeds and (b) directions located at the historical ocean current mooring site marked in Figure 4 for near-surface ocean currents at $15 \mathrm{~m}$ depth. As Figure 4 in [2].
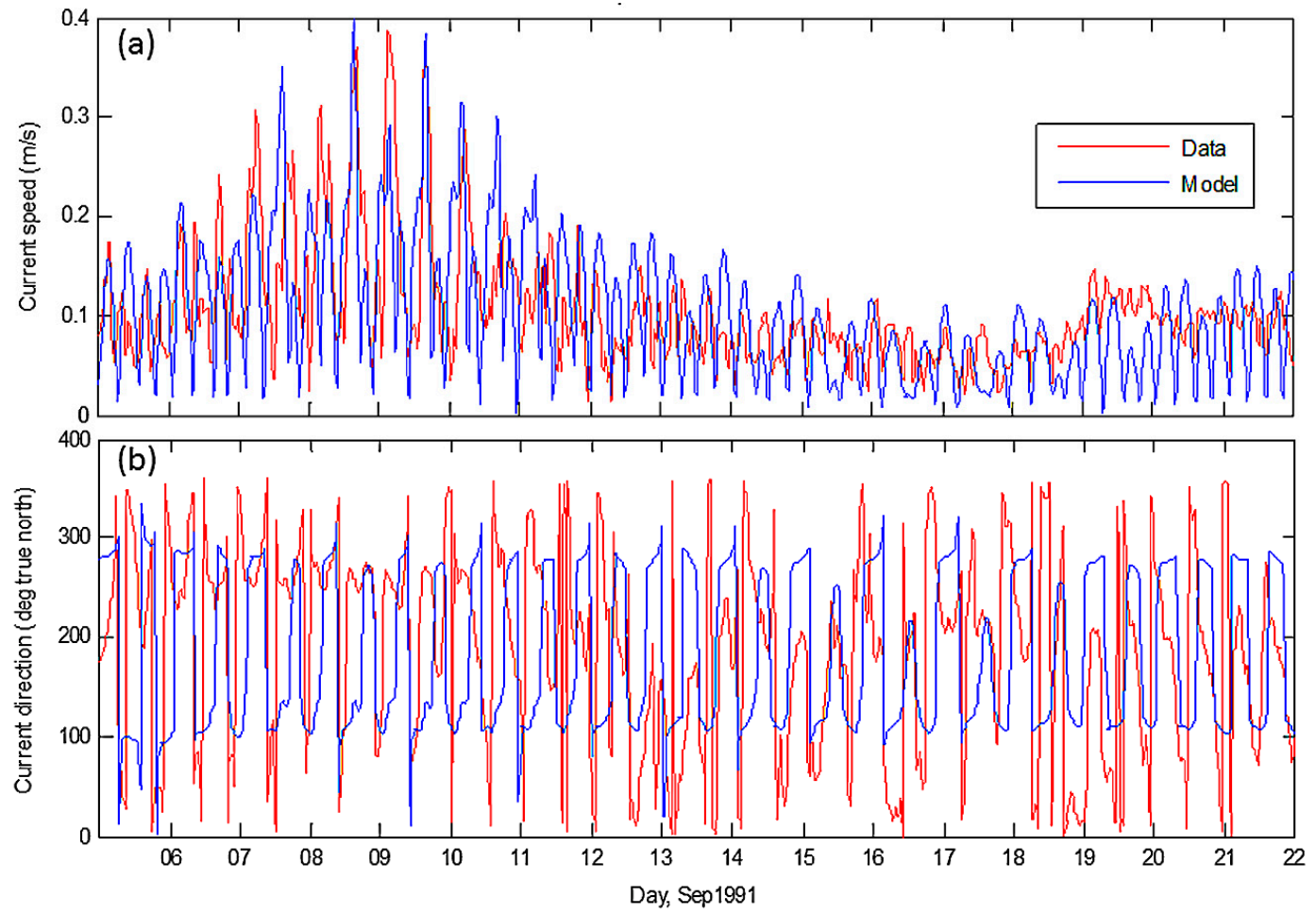

Figure 7. Modeled and measured results of current (a) speeds and (b) directions located at the historical ocean current mooring site marked in Figure 4 for ocean currents at $98 \mathrm{~m}$ depth. As Figure 5 in [2]. 


\section{Near-Bottom Current Measurements in Brown Passage}

The first modern oceanographic measurement program for the near-bottom currents in Brown Passage was conducted from mid-October 2014 to April 2015. The measurements were made at a location in approximately $200 \mathrm{~m}$ water depth within a previously used ocean disposal site (Figure 8). The mooring configuration was a tautline mooring ASL-DualCage frame supporting an upward-looking acoustic Doppler current profiler (ADCP, $300 \mathrm{kHz}$ ) to collect current data through the majority of the water column and a single point current meter (Teledyne doppler volume sampler, DVS) mounted to tandem PORT acoustic releases to measure currents within the bottom $5 \mathrm{~m}$. As well, an RBR XR-420 CTD+Tu instrument was mounted to the DualCage to collect temperature, salinity, and turbidity data (Figure 9). It should be noted that line lengths and heights provided in this image are only approximate. The DVS stopped operating on 9 March 2015, about one month prior to the recovery operations due to an instrument malfunction.

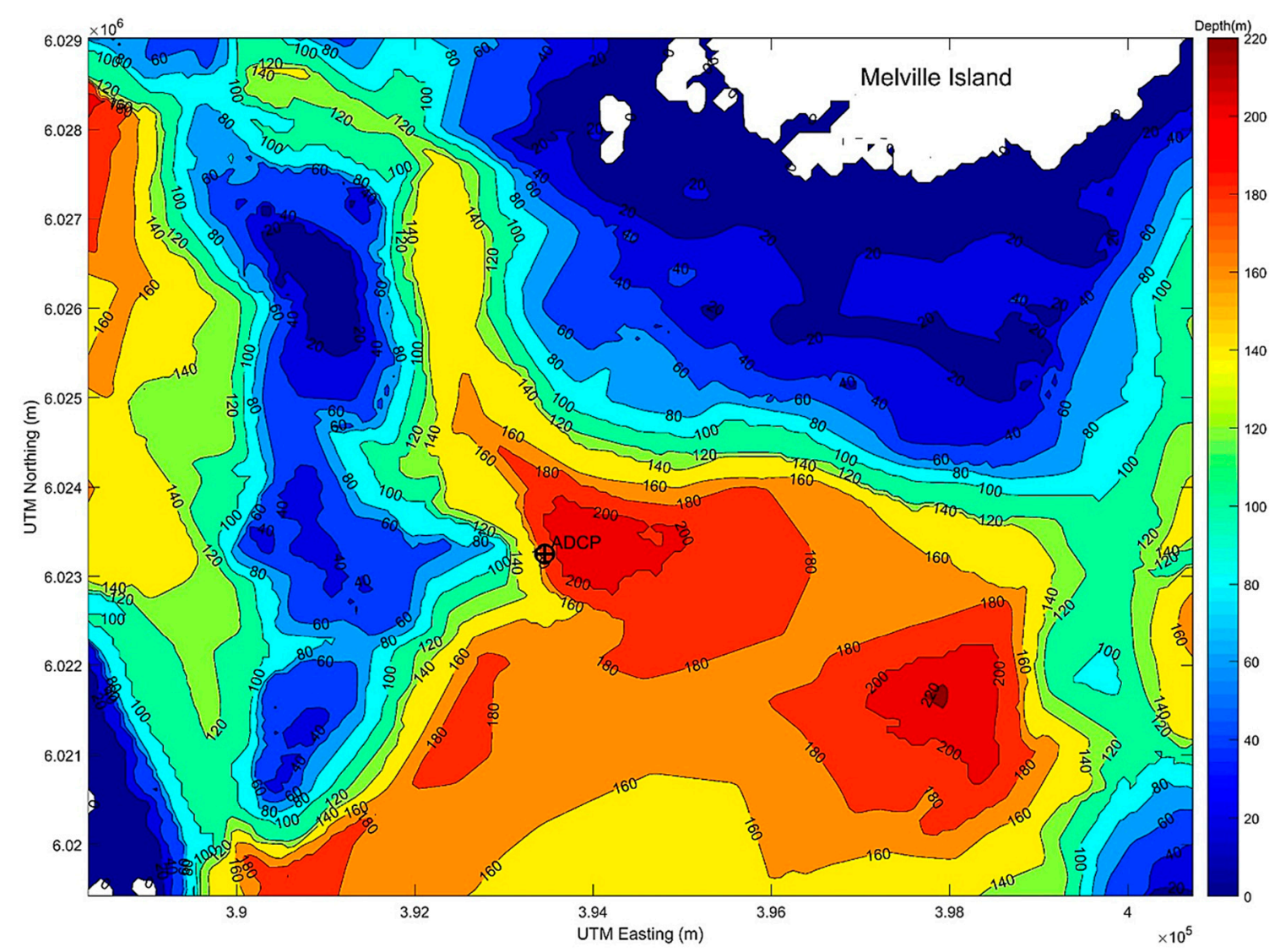

Figure 8. Study area including bathymetry (contours depths below chart datum) and the location of acoustic Doppler current profiler (ADCP) measurements.

Full water column velocities were analyzed at all levels with valid data obtained by the ADCP instrument every $15 \mathrm{~min}$. In addition, currents with 15-min intervals at a single water depth were derived from the DVS (doppler volume sampler) measurements. Plots of speed and direction are shown in Figure 10 for the full water column. The baroclinicity of the flow field was established especially through the directional variability of near-bottom flows, which shows episodes of relatively strong currents in the bottom layers (as red colored bottom areas in Figure 10b) relative to those at mid-depth levels. 


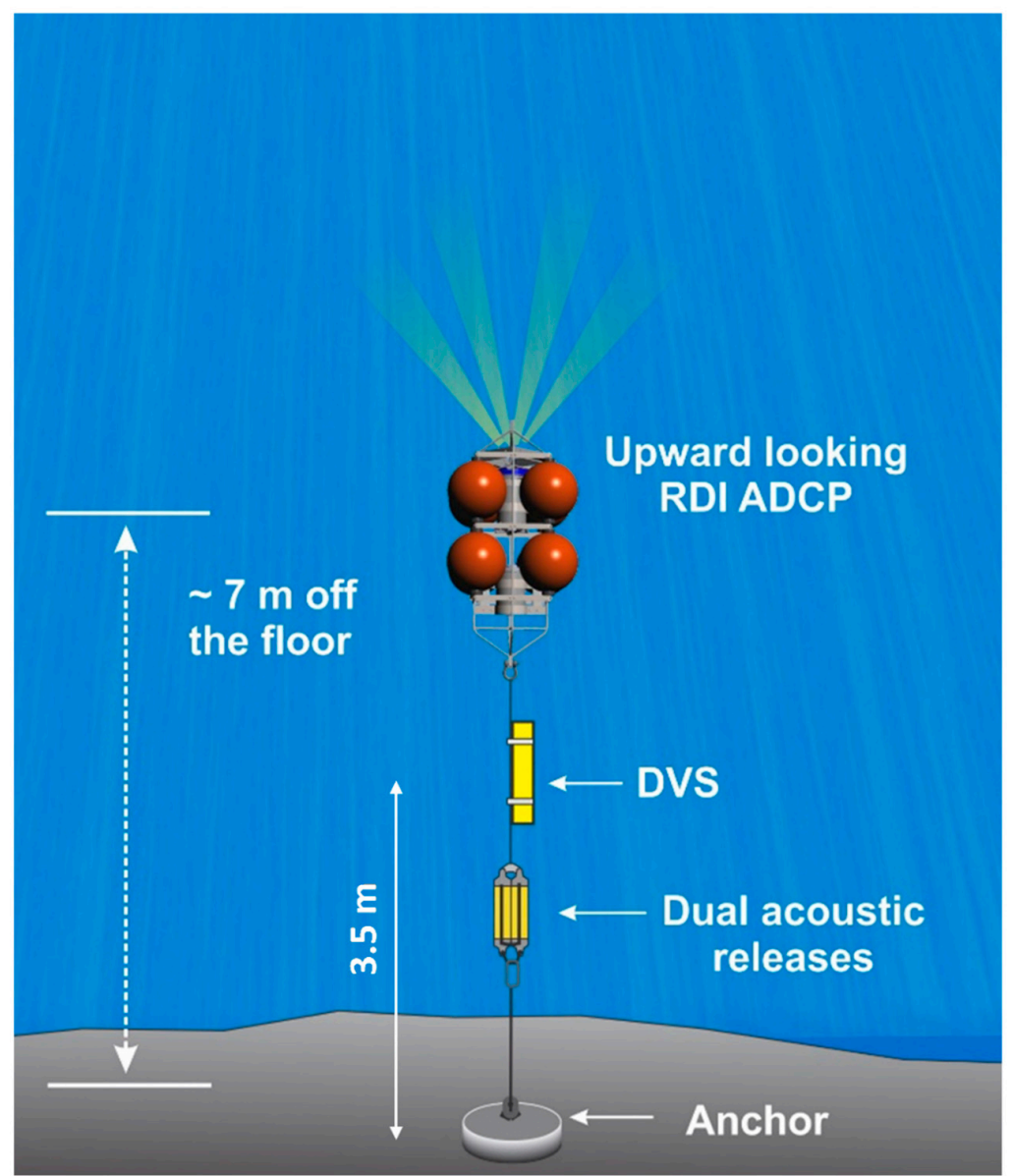

Figure 9. Mooring configuration.
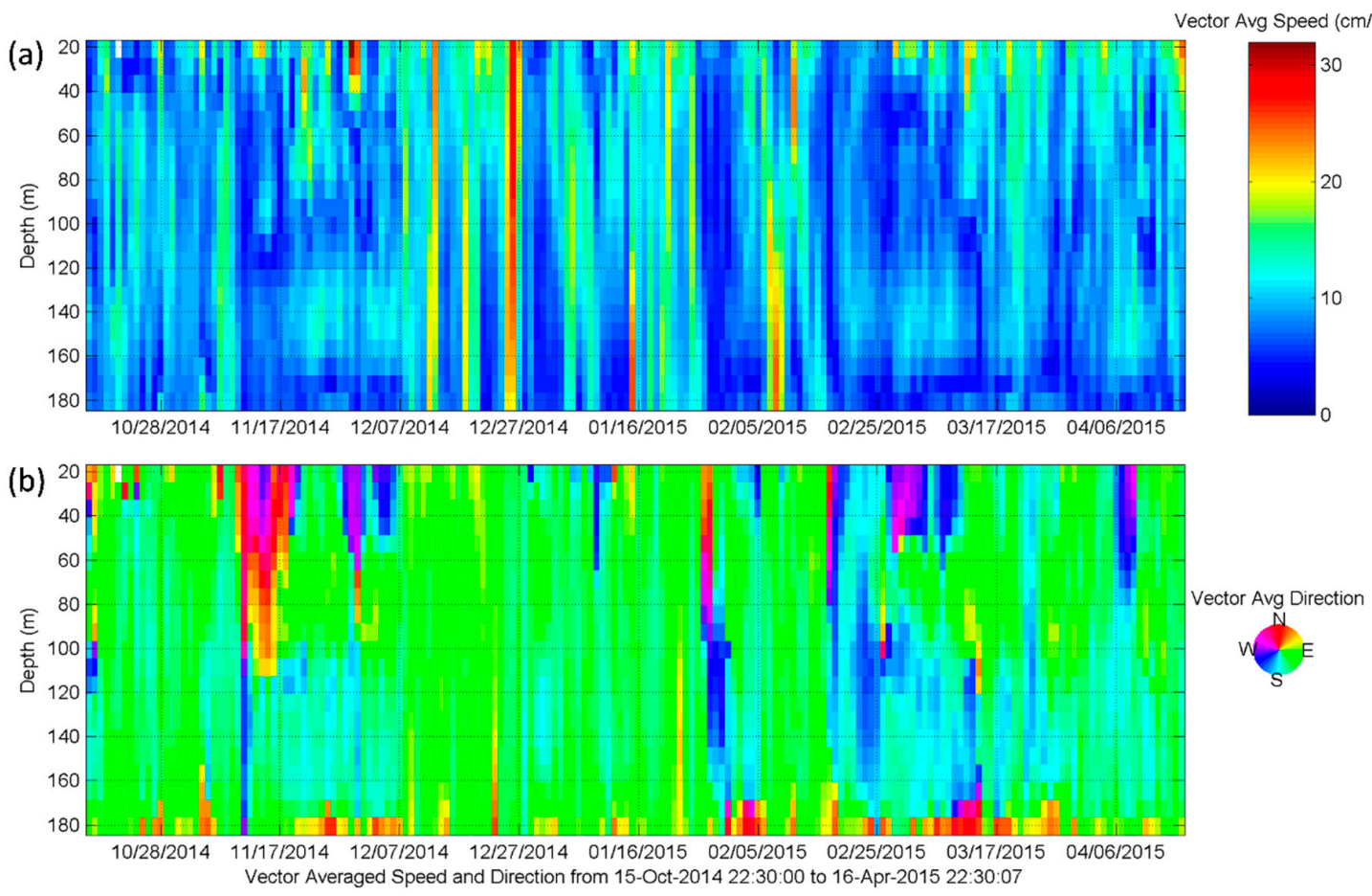

Figure 10. Daily vector average current (a) speed and (b) direction for the full water column. 
The lowest current speeds were observed in the middle of the water column $(133 \mathrm{~m})$ rather than near the bottom of the water column, as is more usually the case. The measured current speeds at mid-depth levels are generally consistent with the historical DFO measurements at a nearby location (see Figure 4) at $98 \mathrm{~m}$ depth. The 99th percentile current speed from the DFO site was $32 \mathrm{~cm} / \mathrm{s}$ as compared to a value of $38 \mathrm{~cm} / \mathrm{s}$ at $98 \mathrm{~m}$ measurement depth in the ADCP program.

Larger current speeds occur at near-bottom levels within $25-30 \mathrm{~m}$ of the seabed. The 99 th percentile current speed is $36 \mathrm{~cm} / \mathrm{s}$ at $133 \mathrm{~m}$ water depth, increasing to $40 \mathrm{~cm} / \mathrm{s}$ at $181 \mathrm{~m}$ depth and $53 \mathrm{~cm} / \mathrm{s}$ at $196 \mathrm{~m}$ water depth, about $3.5 \mathrm{~m}$ above the seabed. The cumulative distribution function (CDF) curves for both observed current speed time series at the deepest ADCP measurement level $(181 \mathrm{~m})$ and at the DVS measurement level (196 m), shown in Figure 11, reveals that the largest observed current speeds are consistently higher just above the seabed over those observed at $15 \mathrm{~m}$ above in the water column. As well as the increased speeds of the currents within $30 \mathrm{~m}$ of the seabed, the ship-based temperature and salinity profile measurements revealed higher densities due to increased salinities in this deep boundary layer of the water column.

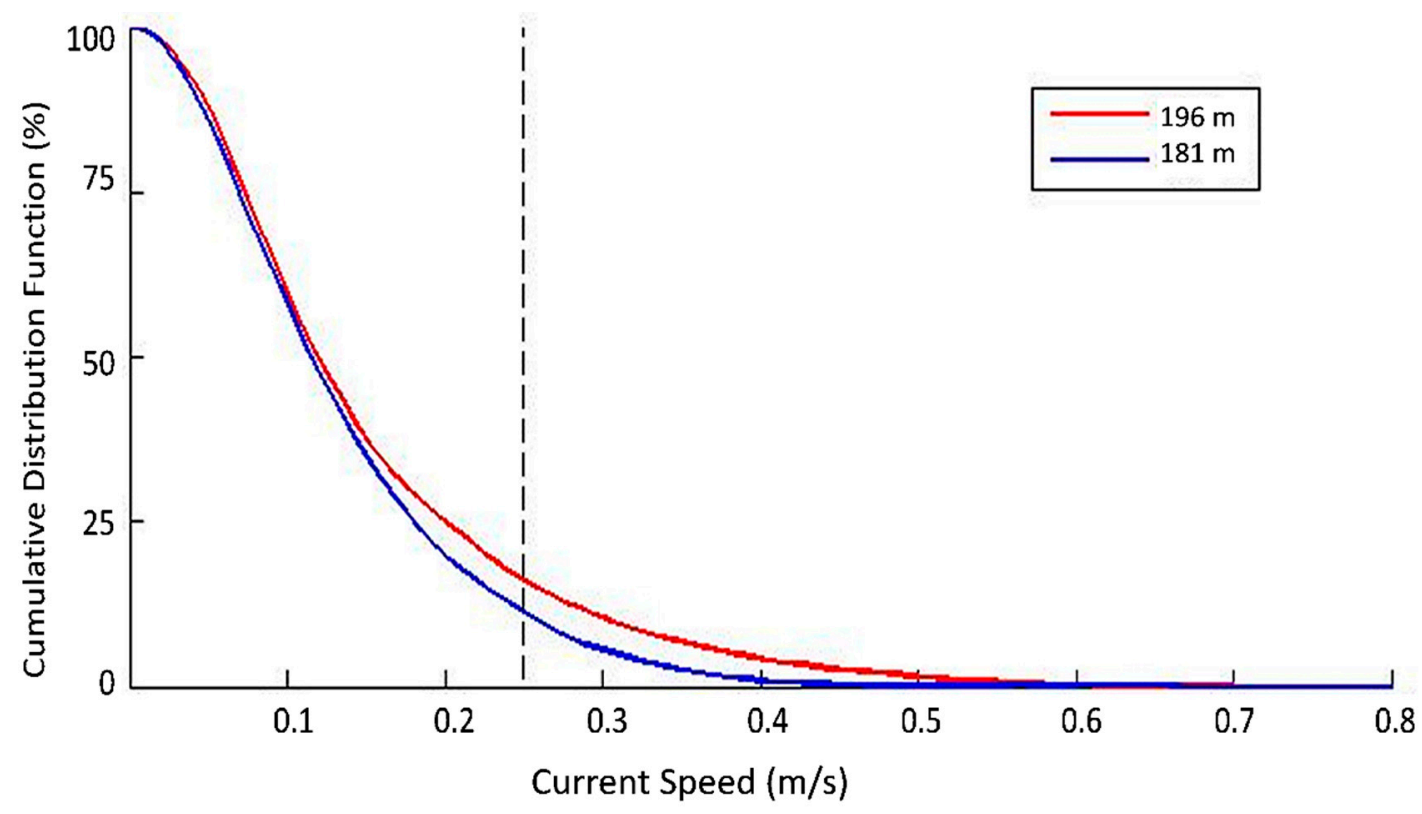

Figure 11. Current speeds at the deepest ADCP measurement level $(181 \mathrm{~m})$ and at the DVS measurement level $(196 \mathrm{~m})$. The vertical dash line marks $25 \mathrm{~cm} / \mathrm{s}$ which is associated with $11 \%$ cumulative distribution function (CDF) (89th percentile) for $181 \mathrm{~m}$ depth and $16 \%$ (84th percentile) for $196 \mathrm{~m}$ depth.

The bottom-mounted CTD-derived time series of temperature and salinity at $7 \mathrm{~m}$ off the seabed show large variations of up to $4{ }^{\circ} \mathrm{C}$ (temperature) and 1 PSU (salinity) occurring episodically over periods of days to weeks. Three groups of CTD casts were completed during the deployment on 15 October 2014, 27 March 2015, and 18-19 April 2015. There were multiple profiles collected each day with variability in association with different tidal phases. The cast-derived density profiles are shown in Figure 12. In fall 2014, the lower half of the water column is occupied by the more saline deep water than seen in the CTD casts. The potential reason is that higher salinity waters from Hecate Strait moved into Brown Passage from the west during this period. To better examine the water structure and the dynamics of the observed deep flow in Brown Passage, a baroclinic hydrodynamic modeling study was carried out in the next section.

The near-bottom currents are observed at depths of $181 \mathrm{~m}$ and $196 \mathrm{~m}$ below chart datum, in the measurements of two different instruments, the ADCP and the DVS, so that the baroclinic signals found in these near-bottom currents are not due to the equipment itself. 


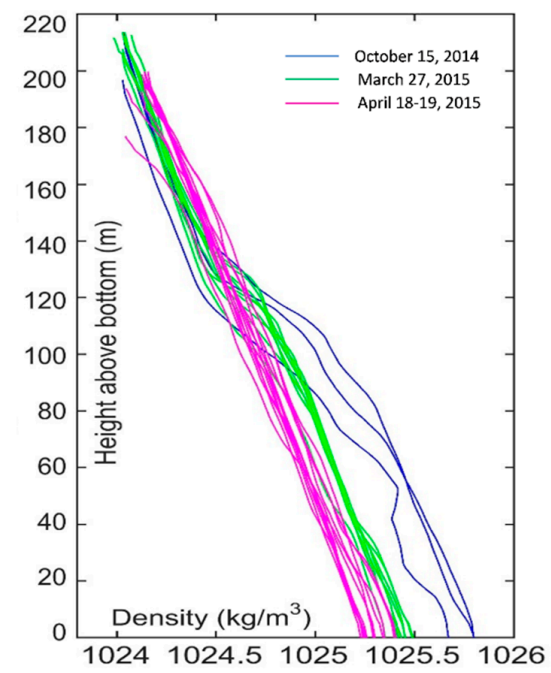

Figure 12. Density profiles as measured by CTD casts during the three periods.

\section{Baroclinic Modeling Study for Deep Flow in Brown Passage}

\subsection{Model Setup}

The 3D hydrodynamic model COCIRM-SED used in this study is based on Jiang and Fissel [2] using the same model domain (Figure 4) and resolution in both the horizontal (100 $\mathrm{m}$ ) and the vertical (22 sigma layers with higher resolutions realized near the surface and bottom). The model was forced at tidal height elevations spanning four open boundaries, and by local surface winds (the remote wind effect is not considered). The surface wind data (applied to model grids at each time step as a uniform value in space) are obtained from the Lucy Island marine weather station (Figure 5b), operated by Environment Canada. Lucy Island winds are more representative of over-water winds for the entire region of study, compared with the overland Prince Rupert Airport winds. However, this would not produce a substantial difference in the deep flow simulation in this study.

In the previous modeling studies, the water column in the Brown Passage was assumed to be well mixed and uniform, essentially barotropic, resulting in minimal flows at the bottom, with current directions as a typical tidal ellipse. In this study, the inputs to the 3D COCIRM-SED model were modified by introducing density stratification due to the vertical changes of salinity (temperature effect is secondary) within the water column. These data were derived from CTD cast data acquired in Brown Passage, as discussed above. The October salinity profiles are selected for initializing the model run (horizontally uniform) and to provide the open boundary conditions from November to December 2014. The selection of the October salinity profiles, rather than March, is to incorporate the higher saline water and associated stronger stratification in the study area.

The following boundary conditions are used. At lateral solid (or closed) boundaries, the normal flow, tangential stress, and normal fluxes of potential temperature and salinity are set to zero (free slip and insulating boundary conditions). Along the model open boundaries, the normal flow, temperature, and salinity fields are adjusted using a method similar to the adaptive open boundary conditions. It first uses an explicit Orlanski radiation condition [18] to determine whether the open boundary is passive (outward propagation) or active (inward propagation). If the open boundary is passive, the model prognostic variables are radiated outward to allow any perturbation generated inside the model domain to propagate outward as freely as possible. If the open boundary is active, the model variables (salinity) at the open boundary are nudged to the CTD profiles (October 2014) at each sigma level with a relaxation time scale of 2 days updated as follows for each time step:

$$
S_{t+1}^{i, k}=S_{t}^{i, k}+\Delta t \epsilon\left(\hat{S}_{t}^{i, k}-S_{t}^{i, k}\right),
$$


where the hat denotes observed salinity, $k$ is the layer number, $k$ is the interface number at open boundaries, and $\varepsilon$ is the relaxation time scale. At inner model grid points, relaxation is not to be performed, and the model predicted variables (salinity) are purely prognostic.

It should be noted that although the model can prognostically simulate the dynamics introduced by the water stratification in Brown Passage, the variability of lower frequency (e.g., the seasonal changes) is limited in the model, due to the referential salinity $\left(\hat{S}_{t}^{i, k}\right)$ used in Equation 1 being set to be constant (in time) along the open boundaries. In order to reproduce the seasonal variability in the baroclinic fields, variable time series of stratification along the open boundaries needs to be applied; measurements of stratification at the open boundaries is not available, and so cannot be included in this preliminary numerical model study.

\subsection{Model Performance}

A model run was carried out for Brown Passage and recently acquired ADCP/DVS current data were used for comparison. After a 3-day spin-up period (based on the development of total kinetic energy in the system) starting at rest, the model was integrated from 1 November to 31 December 2014. Model results were saved every $1.5 \mathrm{~h}$ for analysis.

Table 2 provides a summary of the modeled and observed ocean current speed statistics from 1 November to 31 December 2014, showing the percentile exceedance levels at $99 \%, 95 \%, 75 \%, 25 \%$, and $5 \%$. The model output agrees closely with the observations up to the $75 \%$ percentile. At the $95 \%$ percentile speed, the model underestimates the currents at $21 \mathrm{~m}$ depth by $0.06 \mathrm{~m} / \mathrm{s}$, but the unusually large currents at near-bottom depths of $181 \mathrm{~m}$ and $196 \mathrm{~m}$ are well modeled, being slightly overestimated by $0.04 \mathrm{~m} / \mathrm{s}$ or greater. At the $99 \%$ percentile speed, the model significantly underestimates the $21 \mathrm{~m}$ depth currents by $0.1 \mathrm{~m} / \mathrm{s}$ but, again, the near-bottom currents at $196 \mathrm{~m}$ are within $0.03 \mathrm{~m} / \mathrm{s}$ of the observed value. This demonstrates the model to be performing satisfactory for the purpose of this study, providing conservative results for the current speed estimates in the deeper portions of the water column.

Table 2. Summary of statistics for the modeled and observed current speeds for the maximum, median, and mean values from 1 November to 31 December 2014, showing the percentile exceedance levels.

\begin{tabular}{|c|c|c|c|c|c|c|c|c|c|c|c|}
\hline $\begin{array}{l}\text { Depth } \\
\text { (m) }\end{array}$ & Data & 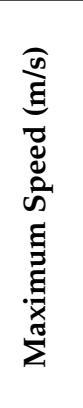 & 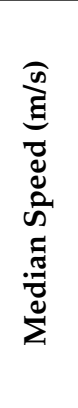 & 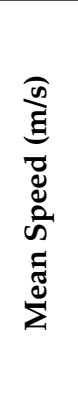 & 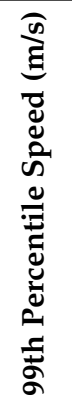 & 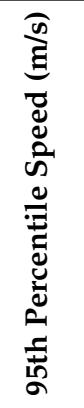 & 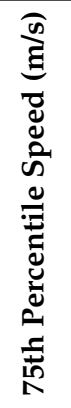 & 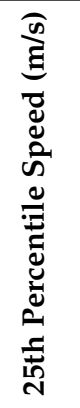 & 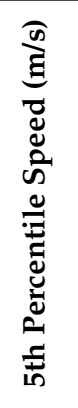 & 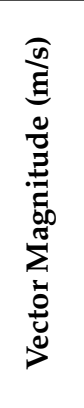 & 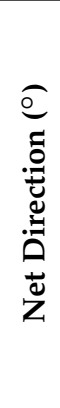 \\
\hline \multirow[b]{2}{*}{21} & OBS & 0.64 & 0.19 & 0.21 & 0.54 & 0.42 & 0.28 & 0.12 & 0.06 & 0.04 & 122 \\
\hline & MOD & 0.52 & 0.17 & 0.19 & 0.44 & 0.36 & 0.24 & 0.12 & 0.06 & 0.07 & 170 \\
\hline \multirow{2}{*}{77} & OBS & 0.58 & 0.13 & 0.16 & 0.51 & 0.35 & 0.21 & 0.09 & 0.03 & 0.07 & 119 \\
\hline & MOD & 0.43 & 0.14 & 0.16 & 0.39 & 0.30 & 0.21 & 0.10 & 0.04 & 0.08 & 174 \\
\hline \multirow{2}{*}{133} & OBS & 0.55 & 0.13 & 0.15 & 0.40 & 0.32 & 0.21 & 0.09 & 0.03 & 0.08 & 141 \\
\hline & MOD & 0.50 & 0.10 & 0.14 & 0.42 & 0.35 & 0.19 & 0.07 & 0.03 & 0.08 & 157 \\
\hline \multirow{2}{*}{181} & OBS & 0.52 & 0.12 & 0.14 & 0.42 & 0.33 & 0.19 & 0.08 & 0.03 & 0.05 & 83 \\
\hline & MOD & 0.55 & 0.12 & 0.15 & 0.48 & 0.41 & 0.23 & 0.07 & 0.03 & 0.08 & 108 \\
\hline \multirow{2}{*}{196} & OBS & 0.66 & 0.12 & 0.16 & 0.57 & 0.42 & 0.21 & 0.08 & 0.03 & 0.08 & 44 \\
\hline & MOD & 0.63 & 0.13 & 0.17 & 0.54 & 0.46 & 0.26 & 0.07 & 0.03 & 0.09 & 89 \\
\hline
\end{tabular}


First, the modeled and ADCP current results from surface to the middle depth at 21, 77, $133 \mathrm{~m}$ are examined (not shown here). Both the model and observed currents exhibited the similar distribution as found by the barotropic run [2] as to the current speeds and directions (see Figures 6 and 7). The currents are typical of tidal channel flows, with flood flow directions ranging from 100 to $150^{\circ}$, and ebb flow directions ranging from 250 to $300^{\circ}$. In the upper layers of the water column, the majority of current speeds are around $0.2 \mathrm{~m} / \mathrm{s}$, and there are only a few instances of flows above $0.3 \mathrm{~m} / \mathrm{s}$.

In this study, we focus on investigating the strong baroclinic near-bottom flow regime. The hourly modeled current fields were saved and extracted at the depths of $181 \mathrm{~m}$ and $196 \mathrm{~m}$ for comparison. Time series of model-derived and observed current speeds and directions between 1 November and 31 December 2014 for the depth of $196 \mathrm{~m}$ are presented in Figure 13. The baroclinic model results for ocean currents near the seabed were found to be of similar magnitude to the strong observed currents, which is an important improvement from its previous barotropic version [2]. A statistical analysis of the baroclinic model results shows that the correlation coefficients between modeled and measured ADCP/DVS current speeds are somewhat weak $(0.23)$ at $196 \mathrm{~m}$. The weak correlation value is believed to be caused by the absence of variability of low frequency water density and subtidal currents through the open boundaries, which is not included in this qualitative study. For example, for the current speeds from 11 to 22 November, in which the model does not replicate large near-bottom flows while, at other times, these large near-bottom flows are present in the model output.
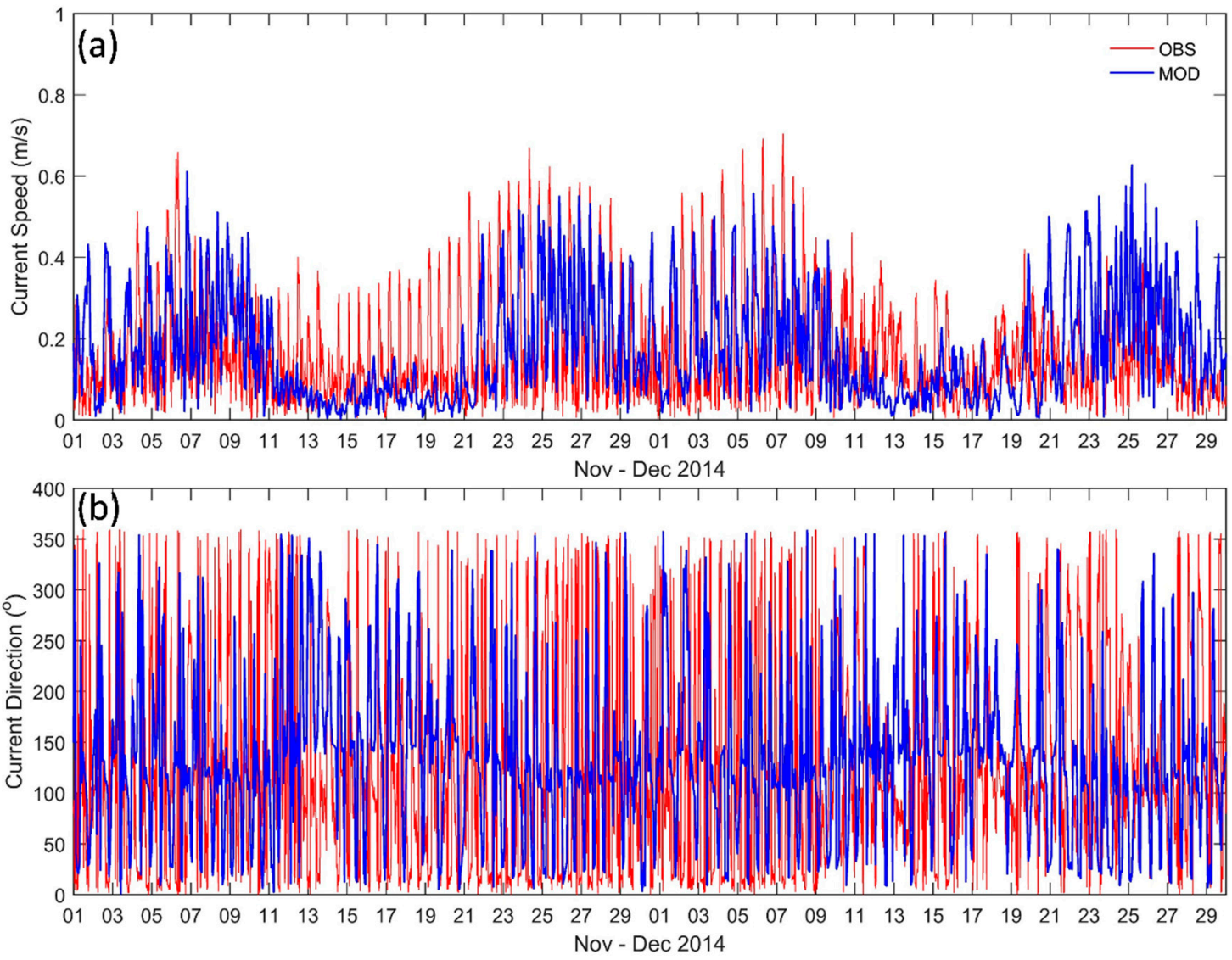

Figure 13. Modeled and measured results located at the ADCP/DVS ocean current mooring site marked in Figure 8 for near-bottom ocean current (a) speeds and (b) directions at the depth of $196 \mathrm{~m}$.

Figure 14 compares the distribution of model-derived and observed current speeds and directions between 1 November and 31 December 2014 for depths of (a) $181 \mathrm{~m}$ and (b) $196 \mathrm{~m}$. Overall, the model results follow the observed values and demonstrated the two modes in the near-bottom flow regime. First, the barotropic mode, which is along the isobath, with an orientation of $120^{\circ}$ (flooding) and $300^{\circ}$ 
(ebbing). In this barotropic mode, near-bottom flood flow can reach $0.5 \mathrm{~m} / \mathrm{s}$ at $181 \mathrm{~m}$ and $196 \mathrm{~m}$, which is stronger than the ebb flow. Second, the newly revealed baroclinic mode is pointing to about $15^{\circ}$ (down-slope, see Figure 8) which is associated with the flood flow. The reversed up-slope flow $\left(195^{\circ}\right.$, see Figure 8$)$ is much weaker, which indicates that the baroclinic mode is mainly driven by the flood tides, i.e., the intrusion of deep higher saline water originating to the west of Brown Passage (i.e., Hecate Strait).
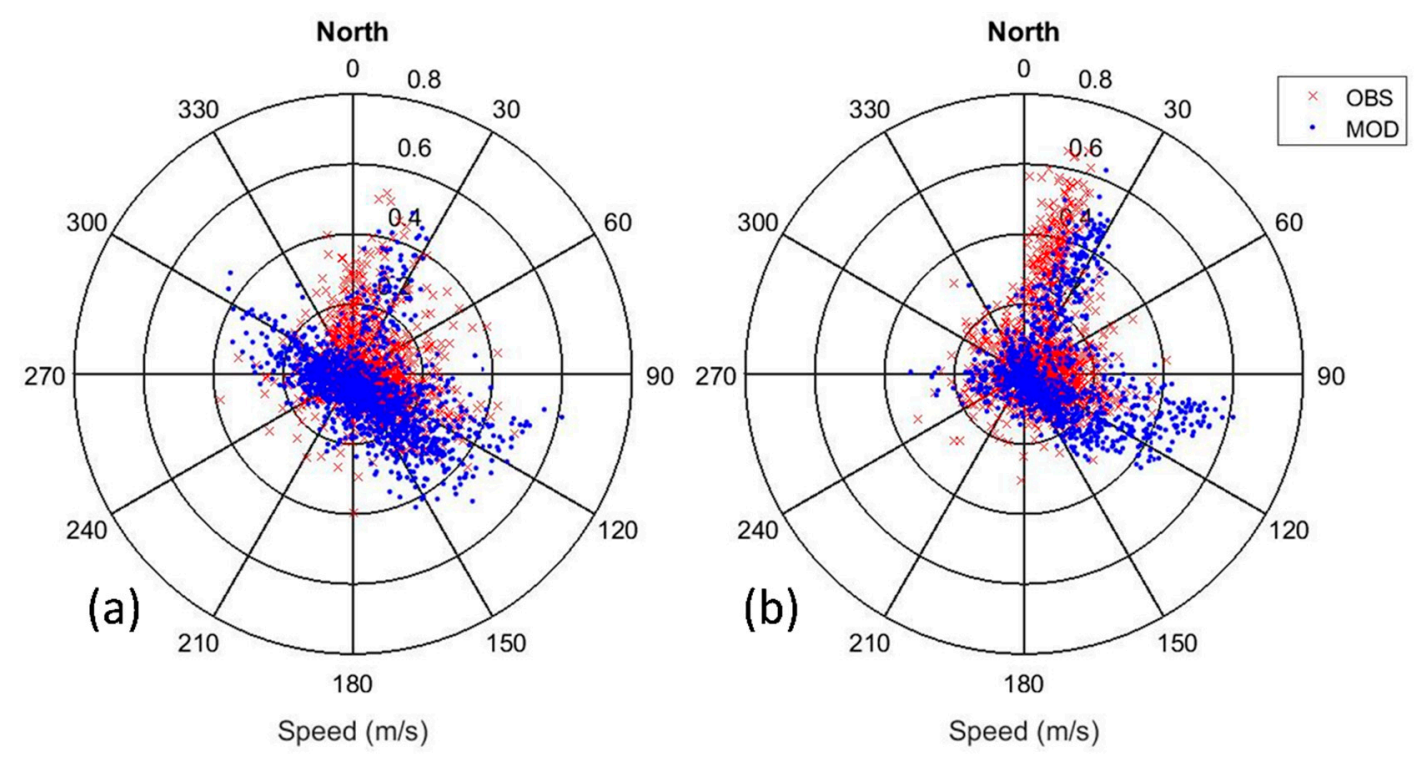

Figure 14. Model results (blue dots) of near-bottom ocean current vectors between 1 November and 31 December 2014, compared with (a) ADCP data (red crosses) at $181 \mathrm{~m}$ and (b) DVS data (red crosses) at $196 \mathrm{~m}$.

Probability density functions of current speeds and directions derived from model results and observations between 1 November and 31 December 2014 were examined in Figure 15. The baroclinic model well reproduced the strong near-bottom speeds, as well as the primary directions. Only slight variations are noted between the modeled and observed near-bottom currents. At the near-bottom depths of 181 and $196 \mathrm{~m}$, the model predicted fewer mid-range currents between 0.1 and $0.2 \mathrm{~m} / \mathrm{s}$ than in the observed results. The percentage of currents between 0.25 to $0.5 \mathrm{~m} / \mathrm{s}$ are slightly overestimated (Figure 15a,b). The results for the current direction comparison between observed and modelled values are summarized in Figure 15 as well. The discrepancies in the modelled predictions are also generally small. As shown in Figure $15 \mathrm{c}, \mathrm{d}$, the model has slightly less frequent northward $\left(330-360^{\circ}\right.$ and $0-30^{\circ}$ at $181 \mathrm{~m} ; 300-330^{\circ}$ and $0-30^{\circ}$ at $\left.196 \mathrm{~m}\right)$ and northeastward near-bottom flows $\left(50-110^{\circ}\right)$, but overestimated the occurrence of southeastward $\left(110-170^{\circ}\right)$ near-bottom flows. The model predicted more northwestward (250-310 $)$ near-bottom flows at the depth of $181 \mathrm{~m}$ (more typically tidal with flows in opposite direction) than the observations, which can also be seen in Figure 14a.

Comparisons with observations for the same period show that the model captured both the low frequency and most of the high frequency variability of the current speed very well. For the lower flow levels relevant to the application of modeling sediment transport and fate from disposal at sea, the model has the capacity to generate representative values and distributions of the near-bottom currents for speed and direction.

\subsection{Discussion}

To demonstrate the effect of the stratification on the deep flow in Brown Passage, a referential barotropic simulation for the exact same period with the baroclinic model have been conducted, by removing the salinity/density field from the modeled variables. The difference of the model-derived near-bottom flow was examined in Figure 16. 

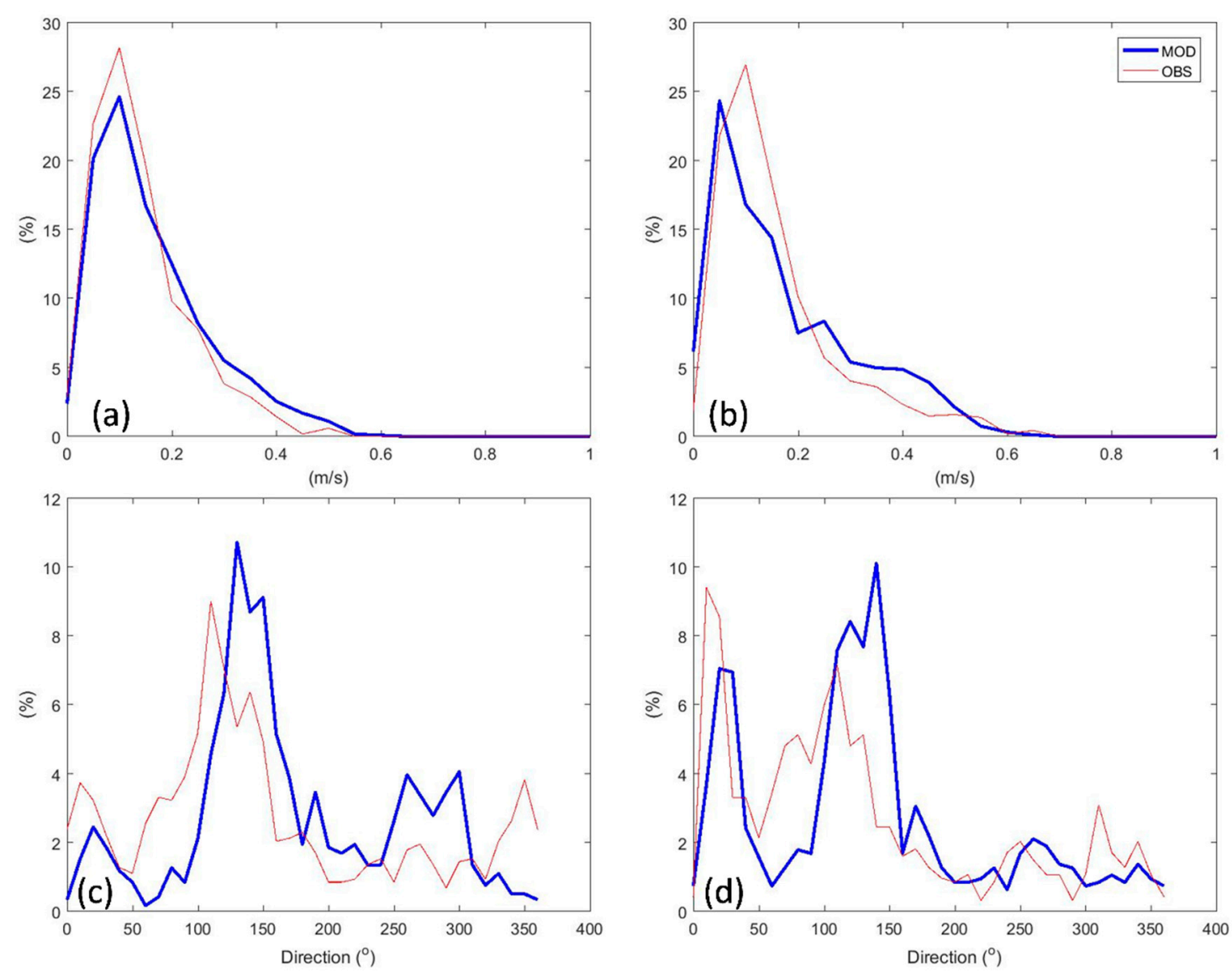

Figure 15. Probability density function of current speeds $(\mathbf{a}, \mathbf{b})$ and directions $(\mathbf{c}, \mathbf{d})$ derived from model results (blue lines) and observations (red lines) between 1 November and 31 December 2014, at (a,c) $181 \mathrm{~m}$ and $(\mathbf{b}, \mathbf{d}) 196 \mathrm{~m}$.

As shown in Figure 16a, the referential barotropic model demonstrated a typical tidal flow pattern in the near-bottom flow regime, aligned with the direction of the isobath. It did not reproduce the strong northeastward down-slope flow as found in the baroclinic model results $(\sim 0.6 \mathrm{~m} / \mathrm{s})$. The barotropic flow also exhibited much weaker flooding flow with directions ranging from $90^{\circ}$ to $130^{\circ}$. The probability density functions of near-bottom current speeds at $196 \mathrm{~m}$ (Figure 16b) indicate that the barotropic model currents has a relatively narrow speed range. The barotropic model underestimated the near-bottom currents with speeds greater than $0.4 \mathrm{~m} / \mathrm{s}$ or less than $0.1 \mathrm{~m} / \mathrm{s}$, compared with the baroclinic model. As to the directional distribution of currents, the barotropic model has less frequent northeastward $\left(0-30^{\circ}\right)$ and southeastward near-bottom flows $\left(100-150^{\circ}\right)$, but overestimated the occurrence of northwestward $\left(310-360^{\circ}\right)$ near-bottom flows (Figure 16c).

Within the two current direction modes of the near-bottom flow as discussed in earlier sections, the strong northward velocity component is found to be the main indicator of the near-bottom baroclinic mode $\left(0-50^{\circ}\right)$. Spectral analysis has been carried out on current speeds from DVS observations and model results from November to December 2014 at the deepest measurement level of $196 \mathrm{~m}$. The power spectral density of the current time series at $196 \mathrm{~m}$ has been calculated, and is shown in Figure 17. The model results are comparable to observations. The energy of the baroclinic near-bottom flow is found to be the largest at the semi-diurnal tidal frequency ( 2 cycles per day) in both model results and observations. Hence, the strong near-bottom flow is believed to be baroclinic semi-diurnal tidal currents (i.e. internal tides). 


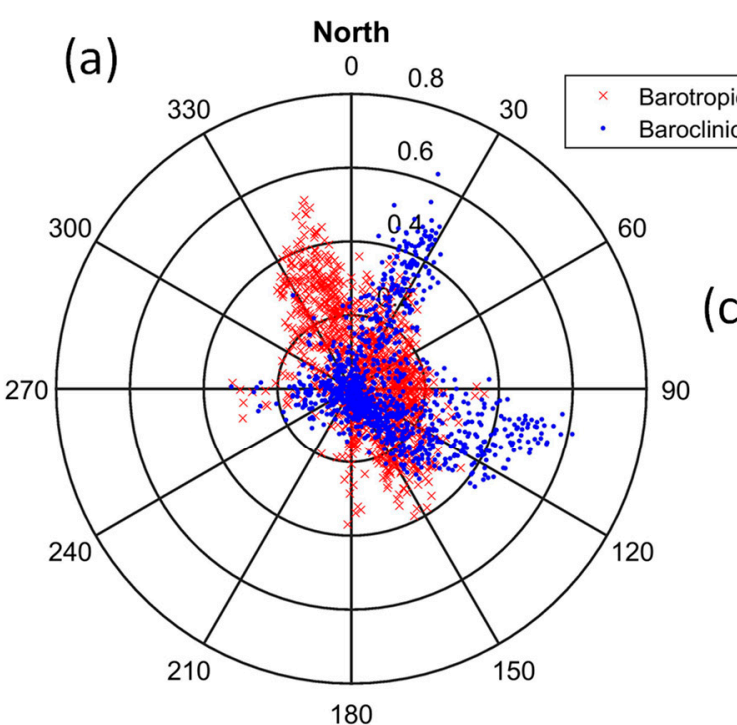

Speed $(\mathrm{m} / \mathrm{s})$ (b)

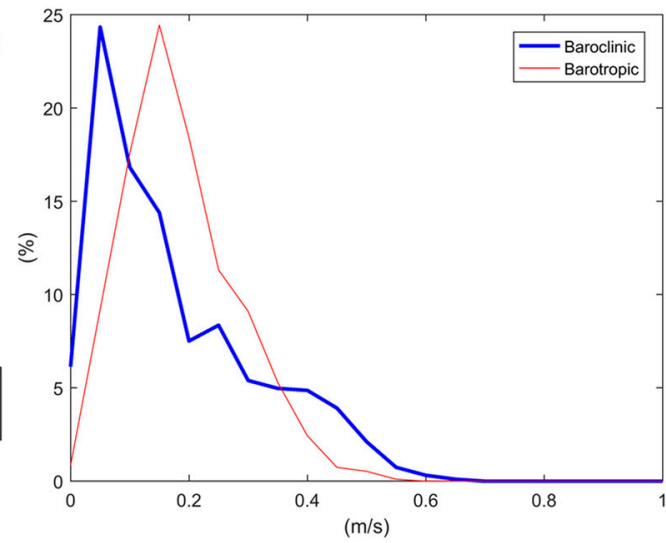

(c)

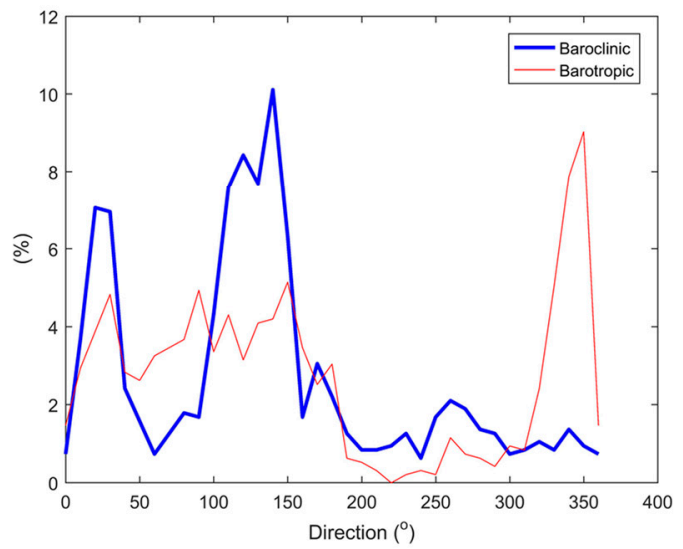

Figure 16. (a) Model-derived near-bottom ocean current vectors at $196 \mathrm{~m}$ from referential barotropic model results (red crosses), compared with baroclinic model results (blue dots) between 1 November and 31 December 2014. Associated probability density function of current speeds (b) and directions (c) derived from the barotropic (blue lines) and baroclinic model results (red lines) are also compared.

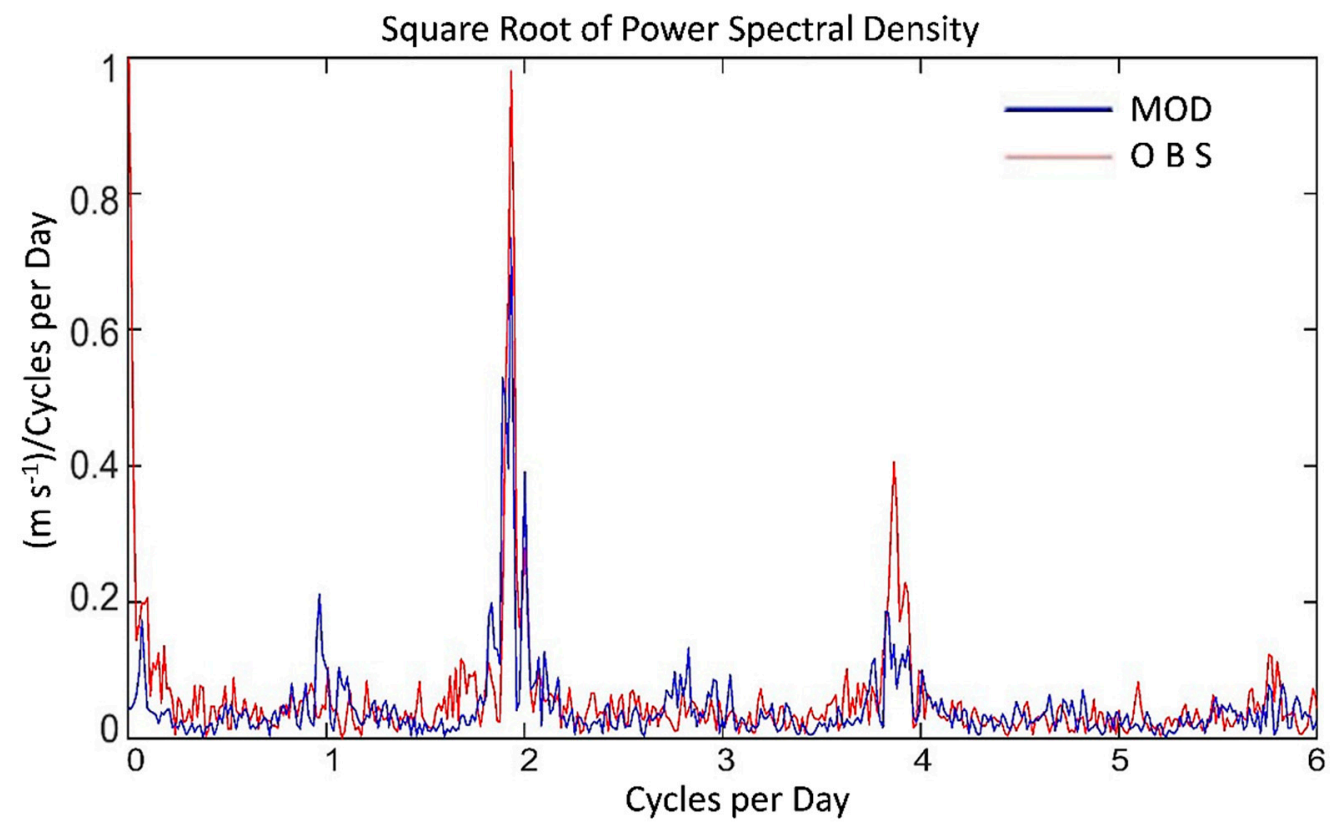

Figure 17. Power spectral density of northward flow component $(\mathrm{m} / \mathrm{s})$ of the near-bottom flow at $196 \mathrm{~m}$ derived from model results (blue line) and observations. 
However, at the very low frequencies of less than 0.2 cycles per day, the model underestimates the power spectrum by comparison with observations, although the total power at these very low frequencies is considerably less than those of the semi-diurnal frequency band. The variability of lower frequency (e.g., the seasonal changes) of the stratification, especially for the higher salinity water intrusion from the west (e.g., Hecate Strait), is not directly represented via the open boundary conditions of this version of the model.

To further investigate the dynamics driving the semi-diurnal tidal currents, time series of density anomalies (time mean removed) measured by the near-bottom CTD unit (Figure 9) during the whole measurement program (later October 2014 to early March 2015) is filtered within the frequency band related to the 9-15 h period (frequency band covering the semi-diurnal variations), as shown in Figure 18. It is clear that there are low frequency variations of bottom density, which is associated with the higher saline water intrusion from Hecate Strait. It is found that the semi-diurnal baroclinic tides, as demonstrated by the large amplitudes of the band filtered density anomalies, is driven by the low frequency high saline water intrusion as seen in the November and December 2014 period.

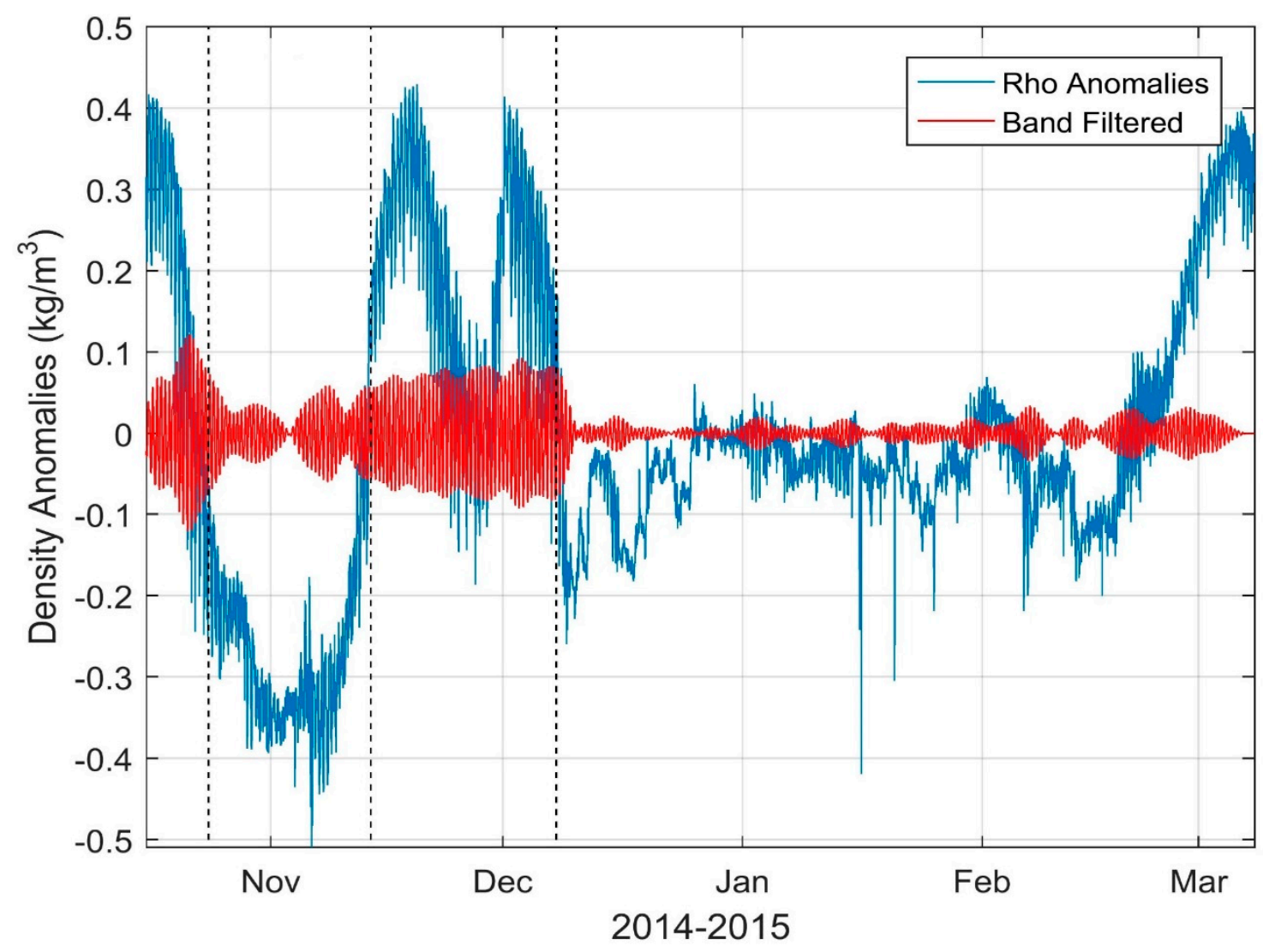

Figure 18. Time series of density (Rho, blue line) anomalies measured by the near-bottom CTD unit. The red line is the band (9-15 h) filtered result.

With the higher salinity and more dense water intrusion in Brown Passage, there is the potential for the semi-diurnal tidal currents to initiate internal waves/tides within the water column along the bottom bathymetry where incident angles or seabed slopes near the critical angle. The Brunt-Väisälä frequency gives an initial insight into the possibility of creating internal waves/tides. The forcing of the barotropic tide is also strong enough in Brown Passage to generate such internal tides so that the M2 tidal constituent can be intensified as shown in both the observed and modeled bottom currents. To better understand the dynamics of the internal tides, additional analysis requiring more extensive observational data sets are required. 


\section{Summary and Conclusions}

Brown Passage is a deep (up to $200 \mathrm{~m}$ ) ocean channel connecting the western offshore waters of Hecate Strait on the Pacific continental shelf with the eastern inland waters of Chatham Sound in Northern British Columbia, Canada. Recent research into this oceanic environment is motivated by studies of the possible use of this area for disposal at sea of dredged sediments arising from expansion of marine terminals in and around Prince Rupert Harbor in Chatham Sound. The ocean currents in Chatham Sound are highly variable due to a combination of forcing by the large tides within this area, winds, and large freshwater discharges from the Skeena and Nass Rivers. Chatham Sea is characterized by lower salinity near-surface waters on its eastern side due to the Skeena River inflow to Southern Chatham Sound [1]. More saline waters present on the western side of Chatham Sound result from the exchange through Brown Passage and other connecting channels with the higher salinity waters of Hecate Strait. A high-resolution 3D finite difference hydrodynamic model (COCIRM-SED) was developed to determine the tidal and wind-driven currents of this area [2], and then used to simulate the transport and deposition of sediments released from activities involving disposal at sea. The model results for ocean currents were found to be comparable with the two sets of ocean current observations at 15 and $98 \mathrm{~m}$ available for Brown Passage, obtained in 1991. Based on these results, Brown Passage was thought to be generally well mixed through the middle and lower parts of the water column.

The first modern oceanographic measurement program carried out to directly determine the near-bottom currents raised questions about the adequacy of the model results for the near-bottom currents in Brown Passage. Using moored bottom instruments operated from October 2014 to April 2015, near-bottom ocean currents at $3.5 \mathrm{~m}$ height above seabed were measured, as well as $\mathrm{ADCP} / \mathrm{DVS}$-derived current profile data for currents throughout the full water column. CTD profile measurements were also obtained during the deployment and recovery of the bottom-mounted instruments. The measured near-bottom currents were found to be considerably higher than the previous model-derived near-bottom currents. As a result, the COCIRM-SED model was modified and rerun, with the most important change being the use of the observed October 2014 water column density profile in place of the previous barotropic modeling approach. This change led to considerable improvements in the ability of the model to generate episodes of relatively strong currents in the bottom layers, which are shown to be in reasonably good agreement for the near-bottom and deeper ocean currents with the 2014-2015 measurement program, (the 99th percentile current speed can reach $40 \mathrm{~cm} / \mathrm{s}$ at $181 \mathrm{~m}$ depth and $53 \mathrm{~cm} / \mathrm{s}$ at $196 \mathrm{~m}$ water depth).

The inclusion of the resulting density stratification effects to previous oceanographic and sediment transport modeling [2] has improved the ability of the model to generate more realistic near-bottom currents, as shown by the comparison with observed currents at $181 \mathrm{~m}$ and $196 \mathrm{~m}$. The power spectral density of the ocean currents has been calculated, and it is found that the energy of the baroclinic near-bottom flow is dominated by the semi-diurnal tidal frequency ( 2 cycles per day) in both model results and observations. Hence, the strong near-bottom flow is believed to be baroclinic semi-diurnal tidal currents (internal tides). It is suggested that the semi-diurnal baroclinic tides are influenced by the low frequency variations of the higher salinity/density water intrusions from Hecate Strait. The detailed mechanisms for generation of semi-diurnal internal tides within the study area requires additional analysis to identify potential source regions where the bathymetric bottom slope matches the vertical ocean density gradient in the form of the Brunt-Väisälä frequency. This finding is scientifically important to direct further numerical studies on the sediment resuspension from disposal at sea operations [19].

As indicated in Figure 17 (less than 0.2 cycles per day part), it should be noted that although the baroclinic model developed in this study can prognostically simulate the dynamics introduced by the water stratification in Brown Passage, the variability of lower frequency (e.g., the seasonal changes) of the stratification especially for the higher salinity water intrusion from the west (e.g., Hecate Strait) is not directly represented at the open boundary of the model. Beyond this qualitative study, the large-scale intrusions of higher density water entering Brown Passage need to be better represented 
in the baroclinic model, especially for the low frequency variations. Future work will require an expanded model domain to cover not only Brown Passage, but also the outer shelf waters of Hecate Strait and Dixon Entrance. A larger model domain would incorporate the low frequency variability of the higher salinity water intrusion into Brown Passage, which could be related to underlying physical mechanisms, such as remote wind fording. An unstructured grid model is proposed for the future numerical modeling study to allow detailed representation of the complex small-scale bathymetric features of Brown Passage while operating with a manageable number of total grid elements over the much expanded model domain, so as to keep the computational requirements for the model to manageable levels.

Author Contributions: The individual contributions of authors to this article consist of: Conceptualization, Y.L. and D.B.F.; Data Collection and its Preliminary Analysis, T.M. and K.B.; Model Development and Validation, Y.L. and D.B.F.; Formal Analysis, Y.L.; Writing—Original Draft Preparation, Y.L.; Writing-Review \& Editing, D.B.F.; Project Administration, D.B.F. and T.M.

Funding: The research presented in this article received no external funding. The 2014-2015 oceanographic measurements made in Brown Passage were funded by Pacific North West LNG through a contract between ASL Environmental Sciences Inc. and Stantec Consulting Ltd.

Acknowledgments: The assistance of ASL Environmental Sciences Inc. personnel, James Bartlett, Matthew Stone, Ryan Clouston, and Jeremy Lawrence, who contributed to the collection and preliminary processing of the oceanographic data, is acknowledged. We also acknowledge the contributions of Jianhua Jiang, formerly at ASL and presently at Alberta Energy Regulator (AER) to the early model development.

Conflicts of Interest: The authors declare no conflict of interest.

\section{References}

1. Lin, Y.; Fissel, D.B. The ocean circulation of Chatham Sound, British Columbia, Canada: Results from numerical modelling studies using historical datasets. Atmos. Ocean 2018, 56, 129-191. [CrossRef]

2. Jiang, J.; Fissel, D. Modeling Sediment Disposal in Inshore Waterways of British Columbia, Canada. In Proceedings of the International Conference of Estuarine and Coastal Modeling, St. Augustine, FL, USA, 7-9 November 2011. [CrossRef]

3. Lucas, B.G.; Verrin, S.; Brown, R. (Eds.) Ecosystem Overview: Pacific North Coast Integrated Management Area (PNCIMA); Canadian Technical Report; Appendix A: Geology; Fisheries and Aquatic Sciences: Sidney, BC, Canada, 2007; p. 2667.

4. Trites, R.W. The oceanography of Chatham Sound, British Columbia. J. Fish Res. Board Can. 1956, 13, 385-434. [CrossRef]

5. Hannah, C.G.; LeBlond, P.H.; Crawford, W.R.; Budgell, W.P. Wind-driven depth-averaged circulation in Queen Charlotte Sound and Hecate Strait. Atmos. Ocean 1991, 29, 712-736. [CrossRef]

6. Ballantyne, V.A.; Foreman, M.G.G.; Crawford, W.R.; Jacques, R. Three-dimensional model simulations for the north coast of British Columbia. Cont. Shelf Res. 1996, 16, 1655-1682. [CrossRef]

7. Flather, R.A. A tidal model of the northeast Pacific. Atmos. Ocean 1987, 25, 22-45. [CrossRef]

8. Foreman, M.G.G.; Henry, R.F.; Walters, R.A.; Ballantyne, V.A. A finite element model for tides and resonance along the north coast of British Columbia. J. Geophys. Res. 1993, 98, 2509-2531. [CrossRef]

9. Cummins, P.F.; Oey, L.Y. Simulation of barotropic and baroclinic tides off northern British Columbia. J. Phys. Oceanogr. 1997, 27, 762-781. [CrossRef]

10. Foreman, M.G.G.; Crawford, W.R.; Cherniawsky, J.Y.; Henry, R.F.; Tarbotton, M.R. A high-resolution assimilating tidal model for the northeast Pacific Ocean. J. Geophys. Res. Ocean. 2000, 105, 28629-28651. [CrossRef]

11. Jiang, J.; Fissel, D.B.; Topham, D. 3D numerical modeling of circulations associated with a submerged buoyant jet in a shallow coastal environment. Estuar. Coast. Shelf Sci. 2003, 58, 475-486. [CrossRef]

12. Jiang, J.; Fissel, D.B. 3D Hydrodynamic Modeling of Sediment Dynamics on Roberts Bank Fraser River Foreslope, Strait of Georgia, Canada. In Proceedings of the Ninth International Conference on Estuarine and Coastal Modeling, Charleston, SC, USA, 31 October-2 November 2005; pp. 806-823. 
13. Jiang, J.; Fissel, D.B.; Borg, K. Sediment plume and dispersion modeling of removal and installation of underwater electrical cables on Roberts Bank, Strait of Georgia, British Columbia, Canada. In Proceedings of the Tenth International Conference on Estuarine and Coastal Modeling, Newport, RI, USA, 5-7 November 2007; pp. 1019-1034.

14. Jiang, J.; Fissel, D.B. Applications of 3D Coastal Circulation Numerical Model in Assessing Potential locations of Installing Underwater Turbines. In Proceedings of the Eleventh International Conference on Estuarine and Coastal Modeling, Seattle, WA, USA, 4-6 November 2009; pp. 478-493.

15. Foreman, M.G.G. Manual for Tidal Heights Analysis and Prediction (Pacific Marine Science Report 77-10), Institute of Ocean Sciences, Patricia Bay. 1977. Available online: http:/ /www.dfo-mpo.gc.ca/Library/54866. pdf (accessed on 10 October 2018).

16. Smagorinsky, J. General circulation experiments with the primitive equations: I. the basic experiment. Mon. Weather Rev. 1963, 91, 99-164. [CrossRef]

17. Mellor, G.L.; Yamada, T. Development of a turbulence closure model for geographical fluid problems. Rev. Geophys. 1982, 20, 851-875. [CrossRef]

18. Orlanski, I. A simple boundary condition for unbounded hyperbolic flows. J. Comput. Phys. 1976, 21, $251-269$. [CrossRef]

19. Fissel, D.B.; Lin, Y. Modeling the transport and fate of sediments released from Marine Construction Projects in the coastal waters of British Columbia, Canada. J. Mar. Sci. Eng. 2018, 6, 103. [CrossRef]

(C) 2018 by the authors. Licensee MDPI, Basel, Switzerland. This article is an open access article distributed under the terms and conditions of the Creative Commons Attribution (CC BY) license (http://creativecommons.org/licenses/by/4.0/). 